\title{
Light-Driven Translocation of the Protein Phosphatase 2A Complex Regulates Light/Dark Dephosphorylation of Phosducin and Rhodopsin ${ }^{\dagger}$
}

\author{
Bruce M. Brown, Brian L. Carlson, $\stackrel{\star}{\star}$ Xuemei Zhu, Richard N. Lolley, and Cheryl M. Craft* \\ The Mary D. Allen Laboratory for Vision Research, Doheny Eye Institute, and Department of Cell and Neurobiology, \\ Keck School of Medicine of the University of Southern California, Los Angeles, California 90089-9112
}

Received July 1, 2002; Revised Manuscript Received September 5, 2002

\begin{abstract}
In steps of protein purification of bovine retinal protein phosphatase 2A (PP2A), phosducin dephosphorylation activity peaks coelute with a PP2A enzyme complex, shown by peptide sequence analysis to contain a B' subunit, B56epsilon. Other PP2A complexes with a slightly larger $(56.5 \mathrm{kDa}) \mathrm{B}^{\prime}$ subunit (sequenced to be B56alpha) or with the $\mathrm{B} \alpha$ regulatory subunit have no phosducin dephosphorylation activity. Upon exposure to light, a significant increase in the immunoreactive protein level of the A, C, and B56epsilon PP2A subunits is observed in the cytosolic fraction of mouse retina, the phosducin dephosphorylation of which occurs rapidly. During dark exposure, these subunits translocate to the membrane fraction where rhodopsin is slowly dephosphorylated. This PP2A redistribution occurs in less than $1.5 \mathrm{~min}$ and is dependent upon light and not upon an intrinsic circadian rhythm. Forty times more of the A subunit ( $\sim 20 \mathrm{ng} /$ mouse retina) and 9 times more of the $C$ subunit ( $\sim 4 \mathrm{ng} /$ mouse retina) than of the B56epsilon subunit $(\sim 0.45 \mathrm{ng} /$ mouse retina) redistribute, which suggests that the predominant form of the PP2A enzyme complex on the membrane in the dark is a dimer, consisting of only A and C subunits. We observe that the dimer favors phosphorylated opsin as a substrate, while the trimer, particularly the enzyme complex with the B56epsilon subunit, greatly prefers phosphorylated phosducin, with an activity several hundred times those of other substrates that were tested. This light-driven PP2A translocation provides a potential mechanism for efficient dephosphorylation of two critical photoreceptor transduction proteins, cytosolic phosducin and membrane-bound rhodopsin, by the same enzyme.
\end{abstract}

Protein phosphatase $2 \mathrm{~A}(\mathrm{PP} 2 \mathrm{~A})^{1}$ is a serine/threonine phosphatase that regulates diverse cellular processes, including signal transduction. The PP2A enzyme exists either as a dimer $(\mathrm{AC})$ or as a trimer $(\mathrm{ABC})$ complex of subunits: a 36-38 kDa catalytic (C), a 60-65 kDa structural (A), and

$\dagger$ This work is dedicated to Mary D. Allen for her generous support of vision research. Financial support was provided, in part, by the Mary D. Allen Endowment, NIH Grant EY00395 (R.N.L. and C.M.C.), NIH Grant EY03040 (DEI Core Grant), the L. K. Whittier Foundation, the Howard Hughes Medical Institute Research Resources Fund (CMC), and Fight for Sight, Research Division of Prevent Blindness America as an Undergraduate Student Research Fellowship (B.L.C.).

* To whom correspondence should be addressed: Cheryl M. Craft, Ph.D., Mary D. Allen Professor for Vision Research, Doheny Eye Institute, Professor and Chair, Department of Cell and Neurobiology, Keck School of Medicine of the University of Southern California, 1333 San Pablo St., Los Angeles, BMT 401 CA 90089-9112. Telephone: (323) 442-1794. Fax: (323) 442-2709. E-mail: ccraft@usc.edu.

$\doteqdot$ Current address: Molecular and Cell Biology Ph.D. Program, Department of Chemistry, University of California, Berkeley, CA 94720-1460.

${ }^{1}$ Abbreviations: BSA, bovine serum albumin; BZMD, benzamide; cAMP, cyclic adenosine monophosphate; cGMP, cyclic guanosine monophosphate; DAB, 3,3'-diaminobenzidine; DEPC, diethyl pyrocarbonate; DGD, diethylene glycol disterate; DTT, dithiothreitol; ECL, enhanced chemiluminescence; EDTA, ethylenediaminetetraacetic acid; HTP, hydroxylapatite; ICC, immunocytochemistry; L/D, light/dark; MES, 2-( $N$-morpholino)ethanesulfonic acid; MOPS, 4-morpholinepropanesulfonic acid; PDE, phosphodiesterase; Phd, phosducin; PKA, protein kinase A; PMSF, phenylmethanesulfonyl fluoride; PP2A, protein phosphatase 2A; PVDF, polyvinylidene fluoride; ROS, rod outer segments; S-Ag, S-antigen (rod arrestin); SDS-PAGE, sodium dodecyl sulfate-polyacrylamide gel electrophoresis; TCA, trichloroacetic acid. multiple nonhomologous 54-130 kDa regulatory (B) subunits. The gene structure and transcriptional regulation are known for the two catalytic isoforms, $\mathrm{C} \alpha$ and $\mathrm{C} \beta$, which are $97 \%$ identical and were potentially derived through gene duplication (1). Similarly, the A subunit has two isoforms and is firmly complexed with the $\mathrm{C}$ subunit (2). The variable $\mathrm{B}$ regulatory subunits are complex in their nomenclature and in nature and are encoded by at least three distinct gene families: (A) PR55 $\alpha, \beta 1-4, \gamma, \delta(3,4)$, (B) PR72/PR130 $(5)$, and $(\mathrm{C}) \mathrm{B}^{\prime}$. The $\mathrm{B}^{\prime}$ gene family is the most complex with several subfamilies: $\mathrm{B}^{\prime} \alpha 1-3, \mathrm{~B}^{\prime} \beta 1-4, \mathrm{~B}^{\prime} \gamma 1,2$, and $\mathrm{B}^{\prime} \delta$ (6), B56 $\alpha-\epsilon$ (7-9), PR61 $\alpha-\epsilon(10)$, and $\mathrm{B}^{\prime \prime} \delta 1-3$ (11). All these $\mathrm{B}^{\prime}$ and $\mathrm{B}^{\prime \prime}$ subunits have highly conserved areas of sequence homology. Additionally, the B' subunit has at least 10 splice variants derived from the five PR61 genes $(4,5$, $7,10,12-15)$. B subunits control the compartmentalization of PP2A within the cell $(13,16)$, as well as the substrate specificity of the $\mathrm{AC}$ complex through interactions at the variable $\mathrm{N}$ - and $\mathrm{C}$-terminal domains of B (17). Evidence of interconversion among the B subunits exists (17). Viruses have evolved B-like proteins, such as Simian virus 40 small $\mathrm{t}$ antigen and adenovirus E4 $(14,18)$, that override normal PP2A control mechanisms.

In the retina rod photoreceptor, dephosphorylation of phosducin and rhodopsin is catalyzed, at least in part, by PP2A (19-25). Phosducin is a phosphoprotein that modulates the light-activated phototransduction cascade of the vertebrate retina, using dephosphorylation mechanisms that 
regulate its interactions with the $\beta \gamma$ subunits of the G-protein transducin (26-29). In addition to phosducin's $\mathrm{G} \beta \gamma$ interaction, it interacts with SUG1, a subunit of the 26S proteasome (30), and it inhibits the transactivation activity of a retinaspecific transcription factor, Crx (31), implying other potential regulatory functions for phosducin in retinal metabolism and development. Rhodopsin is a photon receptor that is coupled to a G-protein cascade. Amplification of the photon response is shut off by rapid phosphorylation of rhodopsin during illumination by G-protein-coupled receptor kinase 1 (GRK1), which both enhances the binding of arrestin and inhibits the catalytic activation of transducin $(29,32$, $33)$. Subsequently, rhodopsin is slowly dephosphorylated and recycled for activation.

In the retina, light and dark adaptation is necessary because, while at the lowest levels of light, photoreceptors can respond to a single photon of illumination. Background levels of illumination can vary by 10 orders of magnitude. Translocation of components of the visual cascade has been shown to effect photoreceptor adaptation to various levels of background light (34). The components that translocate in response to light include transducin (35-37), rod arrestin $(36,37)$, phosducin $(38)$, crayfish Gq alpha and beta (39, 40 ), crayfish screening pigment granules (40), CaM kinase (41), and Drosophila TRPL channels (42).

In light, efficient dephosphorylation of phosducin by PP2A in the cytosolic fraction of photoreceptor cells is needed to effect a quenching of sensitivity so that degrees of intense light can be distinguished. Under darker conditions, dephosphorylation of rhodopsin on the rod outer segment membrane by PP2A is important for increased light sensitivity, returning this visual pigment to a conformation that favors the capture of another photon. In this report, the subunit composition of the PP2A complex in retinal photoreceptors is presented, and a model is proposed that can explain the increased efficiency of dephosphorylation of phosducin by PP2A in light and rhodopsin in darkness through the translocation of the PP2A enzyme from the membrane fraction in darkness to the cytosolic fraction under conditions of intense light.

\section{EXPERIMENTAL PROCEDURES}

Preparation of PP2A-Phosphorylated Substrates. Phosphorylase $a$ was prepared by incubating $5 \mathrm{mg}$ of phosphorylase $b$ with $3 \mu \mathrm{g}$ of phosphorylase kinase in the presence of $50 \mathrm{mM}$ Tris, $\beta$-glycero-2-phosphate ( $\mathrm{pH} \mathrm{8.2),} 10 \mathrm{mM}$ magnesium acetate, and $1 \mathrm{mM}$ ATP $\left(50 \mu \mathrm{Ci}\right.$ of $\left[\gamma_{-}{ }^{32} \mathrm{P}\right] \mathrm{ATP}$, $6000 \mathrm{Ci} / \mathrm{mmol})$ at $25^{\circ} \mathrm{C}$ for $2 \mathrm{~h}(43,44)$. The reaction was stopped with the addition of enough ammonium sulfate to achieve $70 \%$ saturation. The precipitate was resuspended in $50 \mathrm{mM}$ Tris- $\mathrm{HCl}(\mathrm{pH} 7.3), 1 \mathrm{mM}$ EDTA, and $50 \mathrm{mM}$ 2-mercaptoethanol and dialyzed in the same buffer overnight.

Phosphorylated phosducin was prepared by incubating 0.2 $\mathrm{mg}$ of purified bovine phosducin with 100 units of cAMPdependent protein kinase, catalytic subunit (Calbiochem Corp.), in the presence of $62.5 \mathrm{mM}$ MES buffer ( $\mathrm{pH}$ 6.9), 3 $\mathrm{mM}$ 2-mercaptoethanol, $2 \mathrm{mM}$ magnesium acetate, $1 \mathrm{mM}$ BZMD, $0.1 \mathrm{mM}$ PMSF, and $0.4 \mathrm{mM}$ ATP $\left(40 \mu \mathrm{Ci}\right.$ of $\left[\gamma_{-}{ }^{32} \mathrm{P}\right]-$ ATP, $6000 \mathrm{Ci} / \mathrm{mmol}$ ) at $30{ }^{\circ} \mathrm{C}$ for $2 \mathrm{~h}(45)$. The reaction was stopped with $70 \%$ ammonium sulfate, and the precipitate was resuspended in $1 \mathrm{~mL}$ of $50 \mathrm{mM}$ Tris- $\mathrm{HCl}(\mathrm{pH} 7.6), 50$ $\mathrm{mM}$ 2-mercaptoethanol, and $1 \mathrm{mM}$ BZMD and dialyzed overnight in the same buffer.
Phosphorylated opsin was prepared using dark-adapted rod outer segments (ROS) from 25 bovine retinas that were suspended in the dark in $1 \mathrm{~mL}$ of $67 \mathrm{mM}$ potassium phosphate (pH 7.0), $1 \mathrm{mM}$ DTT, and $0.1 \mathrm{mM}$ EDTA (46). The ROS contained endogenous rhodopsin kinase that, upon exposure to light, phosphorylated the freshly bleached rhodopsin over a $60 \mathrm{~min}$ incubation in medium $\left(25^{\circ} \mathrm{C}\right)$ containing $2 \mathrm{mM}$ magnesium acetate and $0.1 \mathrm{mM}$ ATP (40 $\mu \mathrm{Ci}$ of $\left[\gamma^{32}\right.$-P]ATP, $\left.6000 \mathrm{Ci} / \mathrm{mmol}\right)$. The incubated ROS were washed with ice-cold $50 \mathrm{mM}$ Tris- $\mathrm{HCl}$ buffer ( $\mathrm{pH} \mathrm{7.0)}$ and then dialyzed in the same buffer.

Phosphorylated histone was prepared by incubating $10 \mathrm{mg}$ of type VII-S histone (Sigma) in $50 \mathrm{mM}$ Tris- $\mathrm{HCl}$ (pH 7.6), $5 \mathrm{mM} \mathrm{MgCl} 2,1 \mathrm{mM}$ DTT, and $0.5 \mathrm{mM} \mathrm{ATP}(40 \mu \mathrm{Ci}$ of [ $\gamma^{32}$-P]ATP, $\left.6,000 \mathrm{Ci} / \mathrm{mmol}\right)$ for $4 \mathrm{~h}$ at $37^{\circ} \mathrm{C}$. The protein was TCA precipitated and dialyzed in $50 \mathrm{mM}$ Tris- $\mathrm{HCl}(\mathrm{pH}$ 7.6).

PP2A Enzyme Assay. Phosphatase enzyme activity was assayed by incubation for $2-60 \mathrm{~min}$, as determined for the linearity of the reaction, at $30^{\circ} \mathrm{C}$ in a total volume of $60 \mu \mathrm{L}$ in the presence of $10 \mu \mathrm{L}$ of enzyme source, $1 \mu \mathrm{mol}$ of ${ }^{32} \mathrm{P}-$ labeled substrate, $50 \mathrm{mM}$ Tris- $\mathrm{HCl}$ (pH 7.6), $1 \mathrm{mg} / \mathrm{mL}$ BSA, $0.5 \mathrm{mM}$ EDTA, and $2 \mathrm{mM} \mathrm{MnCl}$. The reaction was stopped by the addition of $100 \mu \mathrm{L}$ of $17.5 \%$ TCA followed by 100 $\mu \mathrm{L}$ of $6 \mathrm{mg} / \mathrm{mL}$ BSA, and the mixture was cooled on ice for $30 \mathrm{~min}$ and centrifuged at $13000 \mathrm{~g}$ for $3 \mathrm{~min}$. A $200 \mu \mathrm{L}$ aliquot of the supernatant was counted in a Beckman LS 6500 scintillation counter in the presence of scintillation cocktail (BioSafe II, RPI Corp.).

PP2A Purification. Four hundred dark-adapted frozen bovine retinas (Lawson Co.) were thawed in darkness as they were homogenized in a ceramic mortar and pestle in Ringers buffer (10 mM MOPS, $60 \mathrm{mM} \mathrm{KCl}, 30 \mathrm{mM} \mathrm{NaCl}, 5 \mathrm{mM}$ $\mathrm{MgCl}_{2}, 1 \mathrm{mM}$ DTT, and $0.1 \mathrm{mM}$ PMSF) with 55\% sucrose and passed through an 18 gauge needle, before dilution with Ringers buffer to $38 \%$. The mixture was centrifuged for 20 $\mathrm{min}$ at $27000 \mathrm{~g}$ to separate photoreceptor rod outer segments (ROS) from other components of the retina $(47,48)$. Suspended ROS were diluted with an equal volume of Ringers buffer and pelleted by centrifugation at $40000 \mathrm{~g}$ for 20 min, and the supernatant was retained for PP2A purification.

The ROS supernatant was applied to a $5 \mathrm{~cm} \times 5 \mathrm{~cm}$ DE 52 column (Whatman) equilibrated in $200 \mathrm{mM}$ Ringers buffer, washed with $200 \mathrm{~mL}$ of Ringers buffer, and eluted with $400 \mathrm{~mL}$ of Ringers buffer containing $0.2 \mathrm{M} \mathrm{NaCl}$. The eluate was applied to a $2.5 \mathrm{~cm} \times 11 \mathrm{~cm}$ protamine-agarose column (Sigma) and washed with $50 \mathrm{~mL}$ of Ringers buffer with $0.2 \mathrm{M} \mathrm{NaCl}$ before elution with a $550 \mathrm{~mL}$ gradient of 0.2 to $0.8 \mathrm{M} \mathrm{NaCl}$ in Ringers buffer. The maximum PP2A activity, with phosphorylated phosducin as the substrate, was observed in fractions containing $\sim 0.6 \mathrm{M} \mathrm{NaCl}$. Peak activity fractions were concentrated on an Amicon YM30 membrane (Amicon Corp.) and applied to a $2.5 \mathrm{~cm} \times 90 \mathrm{~cm}$ Ultrogel AcA44 column (IBF Biotechnics) equilibrated in $10 \mathrm{mM}$ $\mathrm{KPO}_{4}, 5 \mathrm{mM}$ DTT, $0.1 \mathrm{mM}$ PMSF, and $1 \mathrm{mM}$ BZMD (pH 6.8). The phosducin activity peak from the Ultrogel column was applied to a $1.6 \mathrm{~cm} \times 5 \mathrm{~cm}$ hydroxylapatite (HTP) column (Bethesda Research Laboratories, Inc.) equilibrated as described above, and eluted with a $50 \mathrm{~mL}$ gradient from $10 \mathrm{mM} \mathrm{KPO}_{4}$ (pH 6.8) to $150 \mathrm{mM} \mathrm{KPO}_{4}$ (pH 7.0) with 1.0 mM EDTA. 
For preparation of purified PP2A subunits for antibody production, the fractions from the HTP column containing activity against phosphorylated phosducin were purified further with a $0.9 \mathrm{~cm} \times 7 \mathrm{~cm}$ heparin-agarose (type II) column, equilibrated in $50 \mathrm{mM} \mathrm{KPO}_{4}, 0.1 \mathrm{mM}$ EDTA, 0.2 $\mathrm{mM}$ PMSF, and 0.2\% (v/v) 2-mercaptoethanol ( $\mathrm{pH} 7.0)$, and eluted with a $150 \mathrm{~mL}, 0$ to $0.5 \mathrm{M} \mathrm{NaCl}$ gradient. Peak PP2A activity $(0.1 \mathrm{M} \mathrm{NaCl})$ against phosphorylated phosducin was pooled for analysis on preparative SDS-PAGE to separate the PP2A subunits. PP2A subunits from several PP2A preparations were pooled for antibody preparation. The subunits were eluted from the preparative SDS-PAGE gel pieces with $\mathrm{NH}_{4} \mathrm{HCO}_{3}$ (pH 8.0), lyophilized, reconstituted in $0.6 \mathrm{~mL}$ of water, and combined with an equal volume of Freud's complete adjuvant for $300 \mu \mathrm{g}$ subdermal injections in rabbits. Booster injections, containing the same subunit dosage in incomplete adjuvant, were administered at 2 week intervals for 10 weeks. The B subunit antibody that was generated was called B56epsilon, after peptide sequence verification of this purified subunit.

For resolution of the purified PP2A trimer from the dimer complex, HTP fractions containing both complexes were applied to a sucrose gradient. Thirteen milliliter gradients of 5 to $20 \%$ sucrose were prepared in $5 \mathrm{mM} \mathrm{MES} \mathrm{(pH} \mathrm{6.9),}$ $100 \mathrm{mM} \mathrm{KCl}, 0.2 \mathrm{mM}$ EDTA, 15 mM 2-mercaptoethanol, and $0.1 \mathrm{mM}$ PMSF. The gradients were spun at $38000 \mathrm{rpm}$ in an SW-40 (Beckman) rotor for $24 \mathrm{~h}$ at $4{ }^{\circ} \mathrm{C}$ and were fractionated from the bottom of the tube into $0.5 \mathrm{~mL}$ samples.

For correlating phosducin dephosphorylation activity with PP2A subunits, particularly various B regulatory subunits, the HTP fractions were electrophoresed on replicate $10 \%$ SDS-PAGE gels. One gel was stained with Coomassie Blue, while the proteins from the other gels were transferred to PVDF membranes for incubation with selected PP2A subunit antibodies.

Molecular Exclusion Calibration of the PP2A Trimer Native Molecular Weight. A Superose 12 column (Pharmacia) was equilibrated in $50 \mathrm{mM}$ Tris- $\mathrm{HCl}(\mathrm{pH} 7.4), 1 \mathrm{mM}$ EDTA, $0.1 \mathrm{mM}$ PMSF, $0.5 \mathrm{mM}$ DTT, and $0.15 \mathrm{M} \mathrm{NaCl}$. Two hundred microliters of the concentrated $0.5 \mathrm{M} \mathrm{NaCl}$ PP2A trimer peak off the protamine-agarose column was applied, and $0.6 \mathrm{~mL}$ fractions were collected (5).

Amino Acid Sequencing. Protein bands correlating with B subunit antibody cross-reactivity were cut from the Coomassie Blue-stained gels of HTP fractions, diced, dried, rehydrated in buffer containing the endopeptidase, trypsin, digested overnight, extracted, concentrated, and subjected to micro-bore C18 HPLC (ABI 172) at the Molecular Structure Facility at the University of California at Davis (Davis, CA). HPLC peaks were sequenced on either the ABI 477A or Procise sequencer and analyzed using 610 software (ABI).

PP2A Developmental Study of Normal and $r d / r d$ Mouse Retinas. Normal C57BL/6J mice and mice with inherited retinal degeneration $(r d / r d)(49,50)$ were exposed to controlled illumination during postnatal development. All animals were treated according to the guidelines stated in the Association for Research in Vision and Ophthalmology resolution on the use of animals in research. Animals were reared on a $12 \mathrm{~h} / 12 \mathrm{~h}$ light/dark (L/D) cycle (lights on at 6:00 a.m. and lights off at 6:00 p.m.) and were sacrificed midday. All retinas were dissected and immediately frozen $\left(-80{ }^{\circ} \mathrm{C}\right)$ until they were used. Six to 18 retinas from each odd postnatal age (P1, P3, P5, etc.) from P1 to P17 and adult (A) (at least 3 months old) were homogenized in $600 \mu \mathrm{L}$ of $50 \mathrm{mM}$ potassium phosphate buffer $(\mathrm{pH}$ 6.8) with protease inhibitors. The retinal homogenates were centrifuged at $13000 \mathrm{~g}$ for $10 \mathrm{~min}$. The supernatants were each assayed for total protein (Bio-Rad), and an equal amount of protein for each postnatal age was applied to SDS-PAGE gels for analysis of PP2A subunits by immunoblots.

Light/Dark Membrane-Cytosol Translocation Study of PP2A Subunits in Normal Mouse Retina. Adult C57BL/6J mice were used for the study. In the light to dark study, one mouse was sacrificed midday and the retinas were immediately dissected under white light and frozen. Three mice were taken to the dark room and sacrificed under infrared light at 1.5, 15, and $30 \mathrm{~min}$ in darkness. Their retinas were immediately dissected under infrared light using two infrared detectors (Owl Dark Invader, Meyers \& Co.) mounted on the dissecting scope and were wrapped in foil and frozen. For the dark to light study, four mice were adapted to dark midday in total darkness for $2 \mathrm{~h}$. One mouse was then sacrificed in the dark, and the retinas were dissected under infrared light. The other three mice were taken into the light and sacrificed at 1.5, 15, and $30 \mathrm{~min}$ in the light, and the retinas were dissected. All retinas were homogenized in 120 $\mu \mathrm{L}$ of $50 \mathrm{mM}$ potassium phosphate buffer ( $\mathrm{pH}$ 6.8) with protease inhibitors and centrifuged at $13000 \mathrm{rpm}$ in a microfuge. The supernatants were assayed for total protein, and the pellets were resuspended in an equal volume of buffer. Both the supernatants and pellets were subjected to immunoblot analysis with antibodies against selected PP2A subunits. The study was repeated independently three times.

Immunoblot Analysis. For the study examining the time course in normal development, $60 \mu \mathrm{g}$ of soluble protein from mouse retinas at each postnatal age was applied to two replicate $11.5 \%$ SDS-PAGE gels. Thirty micrograms of soluble proteins from each time point and an equal volume of the membrane fraction were used in the light/dark redistribution study. The proteins on one gel were stained with Coomassie Blue for total protein to verify equal protein loading, and the proteins on the other gel were electrophoretically transferred to Immobilon-P PVDF membrane and incubated with the primary antibody of interest and an appropriate secondary antibody as previously described (Millipore Corp.) $(51,52)$. Immunoreactive proteins were visualized using enhanced chemiluminescence (ECL) (Amersham), using previously published protocols (53). In some instances, the membranes were stripped and reprobed with additional antisera.

Other Antibodies. Polyclonal antisera recognizing the subunits of PP2A and other proteins were also generated in rabbits according to previous protocols or obtained from other investigators. C. Kamibayashi and M. Mumby (Southwestern Medical Center, Dallas, TX) generously provided several antibodies against the subunits of human PP2A. Antiserum against the human $\mathrm{A}$ subunit was prepared against a human peptide sequence $(\alpha \mathrm{A}-\mathrm{F} 725)$ corresponding to residues 7-19 (DDSLYPIAVLIDE) (54). For the regulatory subunit PP2A $\mathrm{B}^{\prime}$, the antiserum (M878) was prepared against human residues 107-116 (EFDPEEDEPT) (13). For the PP2A B $\alpha$ regulatory subunit, the antiserum (M867) was targeted to human residues 14-26 (FSQVKGAVDDDVA) (54). For the PP2A catalytic subunit, PT-C, a polyclonal antibody 
(M412) was directed against the purified $38 \mathrm{kDa}$ protein phosphatase catalytic subunit from bovine cardiac muscle (55). Other antisera used include AR-1, another general B' subunit antibody against the conserved peptide sequence ELFDSEDPRER, generously provided by D. Pallas (Harvard Medical School, Boston, MA), and monoclonal antibodies Mab C10C10, which recognizes S-antigen (rod arrestin), and 1D6, which recognizes phosducin, both generously provided by L. A. Donoso (Wills Eye Research Institute, Philadelphia, PA) (52, 53). The Pab 1948 antibody, prepared in our laboratory, recognizes retinal creatine kinase (56), and SC261, a polyclonal antibody, recognizes $\mathrm{G} \beta_{1-4}$ (Santa Cruz Biotechnology, Inc.).

\section{RESULTS}

Purification of PP2A from Bovine Retinas. The supernatant of a bovine ROS preparation was subjected to a series of chromatographic procedures (Figure $1 \mathrm{~A}-\mathrm{C}$ ). Fractions were assayed for PP2A activity against phosphorylase $a(\mathbf{\square})$ and phosducin $(\mathbf{\Delta})$. The fractions with the highest phosducin activity, fractions $80-112$ off the protamine-agarose column (Figure 1A), 35-43 off the Ultrogel column (Figure 1B), and 18-29 off the HTP column (Figure 1C), were selected for subsequent purification steps.

Peak PP2A fractions against phosducin (fractions 18-29) from the HTP column were applied to a 5 to $20 \%$ sucrose gradient to separate the PP2A trimer (ABC), which is denser, from the dimer (AC) (Figure 1D). The presence of the trimer or dimer was verified via $11.5 \%$ SDS-PAGE. The trimer had a native molecular mass of $155 \mathrm{kDa}$, a value that is in agreement with the summed mass of a single A (61 kDa), a single $56 \mathrm{kDa} \mathrm{B}$, and a single $\mathrm{C}(38 \mathrm{kDa})$ subunit (Figure 2 ). The trimer has a sedimentation coefficient of 7.3, compared to a sedimentation coefficient of 5.7 for the dimer (Table 1).

PP2A Substrate Specificity of the Trimer $(A B C)$ and Dimer $(A C)$. Sucrose gradient fractions were assayed for PP2A activity against phosphorylated phosducin, histone, opsin, and phosphorylase $a$ (Figure $3 \mathrm{~A}-\mathrm{D}$, left panels). Fractions containing the trimer (fractions 13 and 14) were most active with phosducin or histone and had higher activities than the dimer with these two substrates (Figure 3A,B), while fractions containing the dimer (fractions 17 and 18) had higher activities with opsin or phosphorylase $a$ than those containing the trimer (Figure 3C,D). The specific activities of the trimer and dimer were estimated using quantified densitometric scanning for the PP2A protein and measured PP2A enzyme activity (Figure $3 \mathrm{~A}-\mathrm{D}$, right panels). In some preparations, the specific activity of the PP2A trimer in the sucrose gradient peak fraction, using phosducin as the labeled substrate, was more than $2000 \mathrm{nmol} \mathrm{m^{-1 }}$ (mg of enzyme protein $)^{-1}$, representing a purification from the original ROS supernatant of $\sim 2000$-fold (Table 2).

Correlation of Various PP2A Subunits with the Phosducin Dephosphorylation Peak in the HTP Column. The profiles of the PP2A A and C subunits were similar, with peaks at fractions 16, 20, 30, 38, and 44 (Figure 4B,F). The A and C subunits had constant molecular masses of 61 and $38 \mathrm{kDa}$, respectively, in all five peaks. The dephosphorylation of phosducin peaked in fraction 30 (Figure 4A). Coinciding with
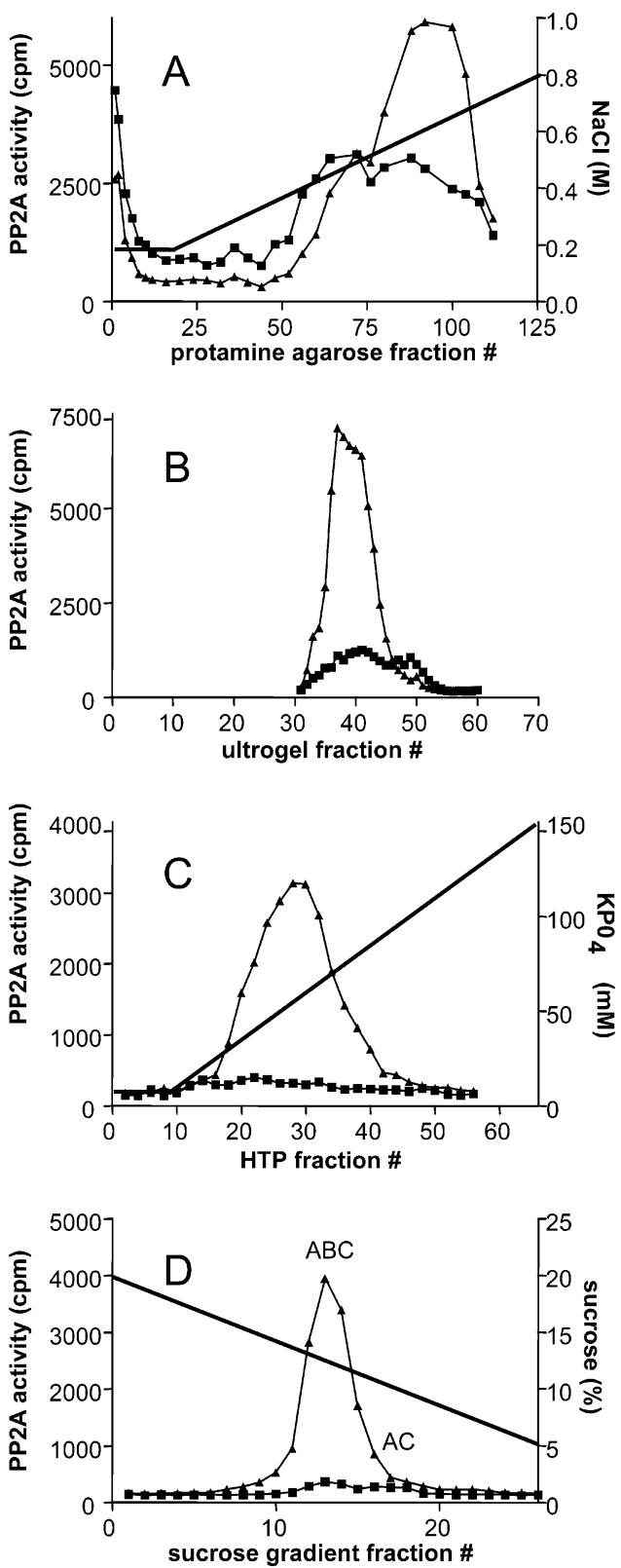

FIGURE 1: Purification of bovine phosphophosducin PP2A. Soluble proteins from 400 bovine retinas were applied to a DE52 anion exchange column and step eluted with $0.2 \mathrm{M} \mathrm{NaCl}$. The DE52 eluate was applied to protamine-agarose (A), Ultrogel molecular exclusion (B), and hydroxylapatite (HTP) (C) columns. For resolution of the PP2A trimer (ABC) and dimer (AC), peak HTP activity fractions were applied to a 5 to $20 \%$ sucrose gradient (D). Fractions were assayed for PP2A activity against phosphorylase $a$ $(\boldsymbol{\square})$ and phosducin $(\boldsymbol{\Delta})$. The fractions with the highest phosducin dephosphorylation activity, fractions $80-112$ off the protamineagarose, 35-43 off the Ultrogel, and 18-29 off the HTP column, were selected for subsequent purification steps. Lines represent the concentrations of $\mathrm{NaCl}(\mathrm{A}), \mathrm{KPO}_{4}(\mathrm{C})$, and sucrose (D). cpm represents counts per minute.

this peak in fraction 30 was one of the five PP2A A (Figure $4 \mathrm{~B}$ ) and $\mathrm{C}$ subunit peaks (Figure 4F). Also coinciding was a $56 \mathrm{kDa} \mathrm{B}$ subunit that was cross reactive with both the $\mathrm{B}^{\prime}$ general antibodies (M878 and AR-1) (Figure 4C) and the B56epsilon antibody (Figure 4D) and sequenced to be B56epsilon. Another B' subunit slightly larger in size (56.5 $\mathrm{kDa}$ ), which was sequenced and identified as B56alpha (Figure 4C, left peak), and $\mathrm{B} \alpha(55 \mathrm{kDa})$ (Figure 4E) eluted from the column in fractions 16 and 44, respectively, and 


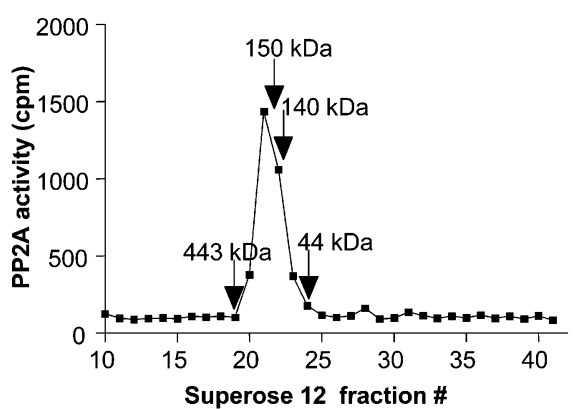

FIGURE 2: Native molecular mass of the bovine retinal PP2A trimer. The PP2A protein complex was concentrated from the protamineagarose column and applied to a Superose 12 (Pharmacia) molecular exclusion HPLC column along with calibration markers: ferritin (443 kDa), yeast alcohol dehydrogenase $(150 \mathrm{kDa})$, lactate dehydrogenase $(140 \mathrm{kDa})$, and horseradish peroxidase (44 kDa). Fractions were assayed against phosphorylated phosducin. The estimated mass of the PP2A trimer $(155 \mathrm{kDa})$ is consistent with a single A $(61 \mathrm{kDa})$, a single B $(54-56 \mathrm{kDa})$, and a single C (38 $\mathrm{kDa})$ subunit. cpm represents counts per minute.

Table 1: Sedimentation Coefficients $\left(S_{20, \mathrm{w}}\right)$ of the Bovine Retina PP2A Trimer and Dimer and Standard Proteins

\begin{tabular}{llc}
\hline \multicolumn{1}{c}{ protein } & fraction & $S_{20, \mathrm{w}}$ \\
\hline $\mathrm{BSA}^{a}$ & $19.5 / 26$ & 4.3 \\
$\mathrm{PP}^{\mathrm{A} A ~ A C}$ & $17 / 26$ & 5.7 \\
$\mathrm{PP}^{b} \mathrm{~A} \mathrm{ABC}$ & & 7.3 \\
yeast alcohol dehydrogenase $^{a}$ & $14 / 26$ & 7.3 \\
fumerase $^{a}$ & $14 / 26$ & 9.0 \\
catalase $^{a}$ & $11 / 26$ & 11.3 \\
\hline
\end{tabular}

${ }^{a}$ Bovine serum albumin, yeast alcohol dehydrogenase, fumerase, and catalase were used to calibrate the 5 to $20 \%$ sucrose gradient that resolved the PP2A. ${ }^{b}$ Dimer. ${ }^{c}$ Trimer. The denser trimer migrated to a position lower in the tube (fraction 14) than the dimer (fraction 17).

therefore did not coincide with the phosducin dephosphorylation. Peak fractions $(16,30$, and 44) were also assayed for rhodopsin dephosphorylation (data not shown). No activity was found in fraction 44 with the $\mathrm{B} \alpha$ subunit. Most of the activity was found in fraction 30 with the B56epsilon subunit, although in substrate preference studies, the enzyme was more active against rhodopsin when the B subunit was dissociated from the AC dimer.

$B$ Subunit Sequencing. The $56 \mathrm{kDa} \mathrm{B}$ subunit that correlates with phosducin dephosphorylation was eluted from the gel and sequenced, which yielded seven peptide sequences (GXLTEQTYPEVVR, LIPLHTV, MVSCNIFR, STLNELVDYITISR, KLEDLELK, QEPLFX, and FMEMNSXMFXELTA), each peptide exactly matching the human sequences described previously: B56epsilon [nucleotide accession number L76703 $(8,9)$, protein accession number NP_006237 (7)] and PR61epsilon [nucleotide accession number Z69029 (10), protein accession number Q16537]. Although the reported nucleotide sequences of the two groups are slightly different, especially in the noncoding region, the amino acid sequences (467 residues) are identical and predict a protein of molecular mass $56 \mathrm{kDa}$. Other reported sequences in rabbit (6), mouse (14), and zebra fish (nucleotide accession number AW778080) are partial sequences, probably of the same protein and, where the sequence is present, match our peptides exactly.

The $56.5 \mathrm{kDa} \mathrm{B}^{\prime}$ subunit, which precedes the B56epsilon subunit off the HTP column in the bovine retinal PP2A purification (Figure 4C), yielded two amino acid sequences
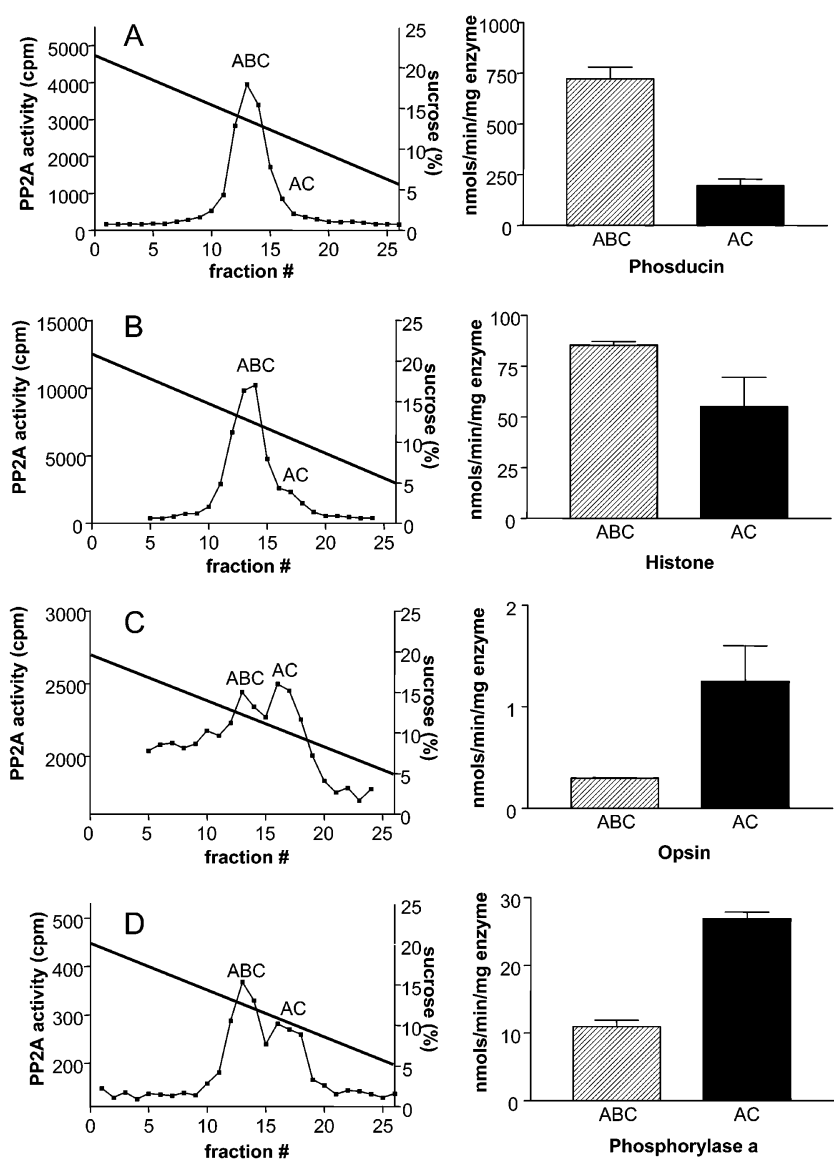

FIGURE 3: Specificity and specific dephosphorylation activity of the trimer $(\mathrm{ABC})$ and dimer $(\mathrm{AC})$ for various substrates. Peak fractions of phosducin dephosphorylation activity from the HTP column were separated on a 5 to $20 \%$ sucrose gradient. Fractions were assayed for PP2A activity against phosphorylated phosducin (A), histone (B), opsin (C), and phosphorylase $a$ (D). Sucrose gradient profiles are shown on the left. The trimer $\left(S_{20, \mathrm{w}}=7.3\right)$ and dimer $\left(S_{20, \mathrm{w}}=5.7\right)$ were verified on $11.5 \%$ SDS-PAGE. Specific activities of the peak trimer (13 and 14) and dimer (17 and 18) fractions are shown on the right. They are the average \pm the standard error of the mean (SEM) for replicate assays and were calculated with enzyme proteins estimated from SDS-PAGE densitometrically scanned and compared to a BSA standard curve.

(EXPDFQPSIA and FTR), both of which match exactly the following human PP2A B' sequence: B56alpha [nucleotide accession number L42373 $(8,9)$, protein accession number Q15172 (7)]. Neither peptide sequence exactly matches any other known $\mathrm{B}^{\prime}$ subunit.

Mouse B56epsilon. To produce enough purified B subunit for sequencing, bovine retinas were used because of their size and availability, but mice were used in our light/dark studies. We believe that the mouse B subunit observed translocating in the light/dark studies is identical to the bovine protein sequenced (B56epsilon), which correlates with phosducin dephosphorylation, because of the following observations. (1) The bovine and mouse proteins have exactly the same molecular mass $(56 \mathrm{kDa})$ when analyzed side by side on a gel (data not shown), and (2) both proteins cross react not only with the $\mathrm{B}^{\prime}$ general antibodies (M878 and AR-1) but also with the B56epsilon antibody made specifically against the bovine retinal B56epsilon purified protein.

Other B Subunits Observed in the Bovine and Mouse Retina. Table 3 summarizes all the PP2A B subunits 


\begin{tabular}{|c|c|c|c|c|c|}
\hline purification step & $\begin{array}{l}\text { total protein }{ }^{a} \\
(\mathrm{mg})\end{array}$ & $\begin{array}{c}\text { total activity }^{b} \\
(\mathrm{nmol} / \mathrm{min})\end{array}$ & $\begin{array}{l}\text { yield }^{c} \\
(\%)\end{array}$ & $\begin{array}{l}\text { specific activityd } \\
\left(\mathrm{nmol} \mathrm{min}{ }^{-1} \mathrm{mg}^{-1}\right)\end{array}$ & $\begin{array}{l}\text { purification }^{e} \\
\quad(x \text {-fold })\end{array}$ \\
\hline ROS supernatant & $4.53 \times 10^{3}$ & $5.13 \times 10^{3}$ & 100 & 1.13 & 1 \\
\hline DE52 & $2.55 \times 10^{3}$ & $5.05 \times 10^{3}$ & 98.1 & 1.99 & 1.74 \\
\hline protamine-agarose & 96.2 & $2.49 \times 10^{3}$ & 46.6 & 25.9 & 22.8 \\
\hline Ultrogel & 20.8 & 459 & 8.94 & 23.1 & 20.8 \\
\hline HTP & 2.88 & 654 & 12.7 & 232 & 20.4 \\
\hline sucrose gradient $(\mathrm{ABC})$ & 0.010 & 23.6 & 0.462 & $2.36 \times 10^{3}$ & $2.03 \times 10^{3}$ \\
\hline
\end{tabular}

${ }^{a}$ The amount of total retinal soluble protein was determined by the Lowry assay modified for the presence of 2-mercaptoethanol. ${ }^{b}$ The total activity was calculated from $10 \mu \mathrm{L}$ of the pooled fractions for each step of the purification against $1 \mu$ mol of phosphorylated phosducin adjusted to the total volume of each step. ${ }^{c}$ The yield is a comparison of the total activities of each step with the activity of the ROS supernatant set arbitrarily at $100 \%{ }^{d}$ The specific activity is calculated by dividing the activity of an aliquot of pooled fractions by the quantity of enzyme protein. ${ }^{e}$ The degree of purification is a comparison of the specific activities of each step with that of the ROS supernatant, set at 1-fold (unpurified). The preparation resulted in a purification of approximately 2000 -fold.
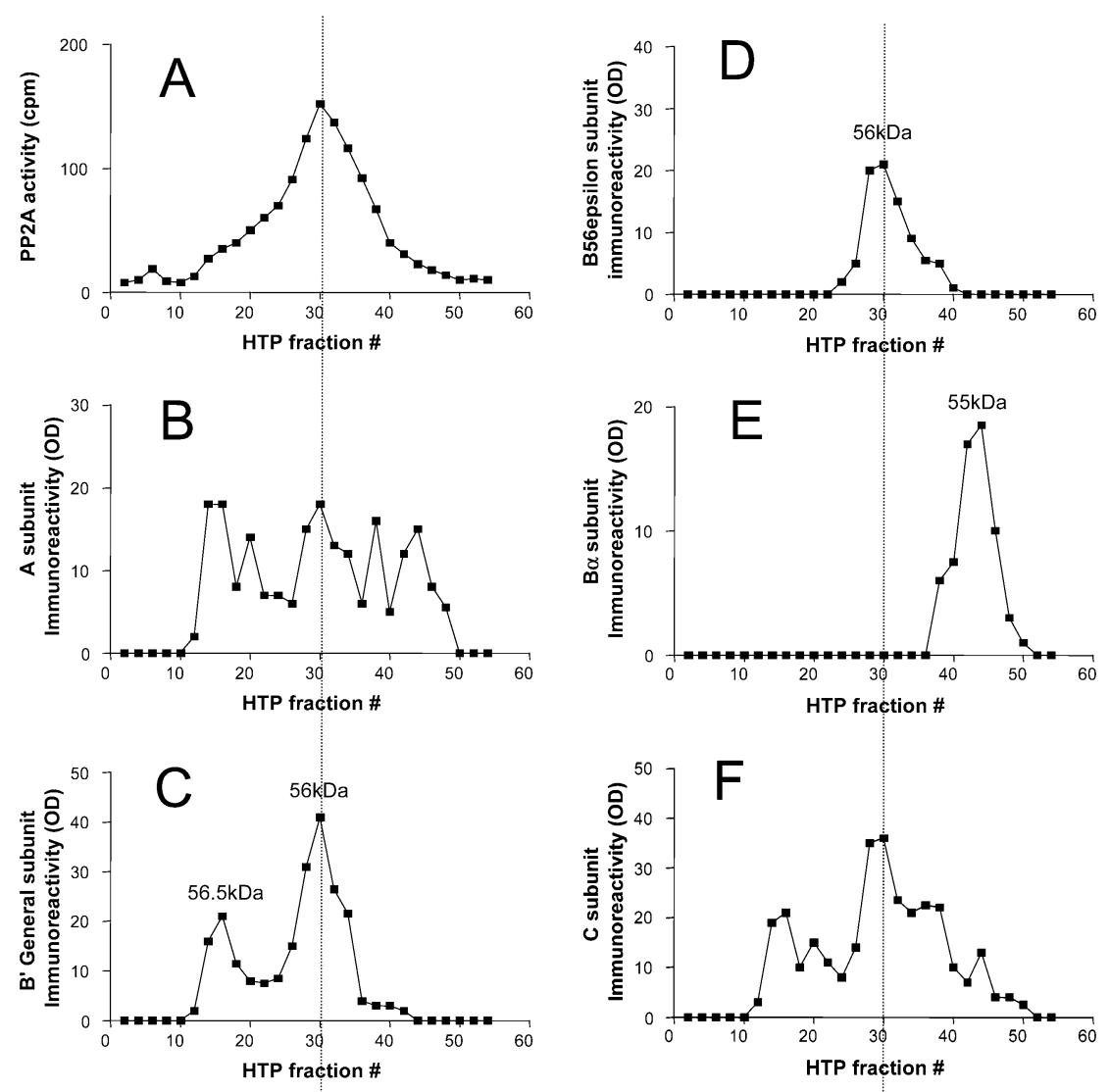

FIGURE 4: Correlation of various PP2A subunits with the phosducin dephosphorylation activity peak on the HTP column. Fractions off the HTP column were analyzed via 10\% SDS-PAGE, electrophoresed, and processed for immunoblot analysis with replicate membranes of transferred proteins. Each membrane was incubated in primary antibody to PP2A subunits as part of the standard ECL protocol. The appropriate band in each fraction was quantitated by densitometric scanning and plotted as the optical density (OD). Phosducin dephosphorylation is shown in panel A. Primary antibodies were as follows: (B) A subunit (human residues 7-19, DDSLYPIAVLIDE, accession number P301583), (C) B' general (human residues 107-116, EFDPEEDEPT, accession number U37352), (D) B56epsilon (against purified B56epsilon from bovine retina), (E) B $\alpha$ (M867, human residues 14-26, CFSQVKGAVDDDVA), and (F) C subunit (M412, the catalytic subunit, PT-C, directed against the purified $38 \mathrm{kDa}$ protein from bovine cardiac muscle). The peak phosducin dephosphorylation activity peak (fraction 30), indicated by a vertical line, coincides with one of the five PP2A A and C subunit peaks (16, 20, 30, 38, and 44) and the $56 \mathrm{kDa}$ B56epsilon subunit, recognized by both the $\mathrm{B}^{\prime}$ and B56epsilon antibodies. A slightly larger B subunit (56.5 kDa) seen by the $\mathrm{B}^{\prime}$ antibody, peaking in fraction 16 , and a $55 \mathrm{kDa} \mathrm{B}$ subunit recognized by the $\mathrm{B} \alpha$ antibody peaking in fraction 44 do not coincide with the phosducin activity peak. These other B subunit peaks have coinciding A and C subunit peaks.

observed in the bovine and mouse retina. In addition to the bovine B56epsilon and B56alpha subunits that have been sequenced, we observed B56epsilon in the mouse retina, $\mathrm{B} \alpha$ in both bovine and mouse retina, and B56delta and $\mathrm{B}^{\prime}$ gamma subunits in the mouse retina.

The peptide used to generate the $\mathrm{B} \alpha$ antibody (CFSQVKGAVDDDVA) exactly matches only two reported B subunits (both closely related), $\mathrm{B} \alpha$ [human protein accession number NP_002708 (4), rat protein accession number P36876 (57)] and B [rat protein accession number AAA41909 (57)]. These sequences are identical except that AAA41909 has a 17amino acid insertion at amino acid 61, compared to NP_002708 and P36876, which are identical. There is no sequence similarity between the $\mathrm{B} \alpha$ and $\mathrm{B}^{\prime}$ subunits. 


\begin{tabular}{|c|c|c|c|c|c|c|}
\hline & species & subunit & $\begin{array}{l}\text { molecular } \\
\text { mass }(\mathrm{kDa})\end{array}$ & $\begin{array}{l}\text { nucleotide accession } \\
\text { number }\end{array}$ & $\begin{array}{l}\text { protein accession } \\
\text { number }\end{array}$ & antibody cross reactivity \\
\hline \multirow[t]{2}{*}{1} & bovine & B56epsilon $^{a}$ & 56 & $\operatorname{L76703}(8,9)^{d}$ & $\mathrm{NP} 006237(7)^{d}$ & $\begin{array}{l}\text { B56epsilon-specific, }{ }^{b} \mathrm{~B}^{\prime} \text { general (M878, EFDPEEDEPT; } \\
\text { AR-1, ELFDSEDPRER) }\end{array}$ \\
\hline & & PR61epsilon ${ }^{e}$ & 56 & $\mathrm{Z} 69029(10)^{d}$ & Q16537 (10) $)^{d}$ & \\
\hline 2 & bovine & B56alpha $^{a}$ & 56.5 & $\operatorname{L} 42373(8,9)^{d}$ & $\mathrm{Q} 15172(7)^{d}$ & $\begin{array}{l}\text { B' general (M878, EFDPEEDEPT; } \\
\text { AR-1, ELFDSEDPRER) }\end{array}$ \\
\hline 3 & bovine & $\mathrm{B} \alpha$ & 55 & - & $\mathrm{NP} 002708(4)^{d}$ & $\mathrm{~B} \alpha(\mathrm{CFSQVKGAVDDDVA})$ \\
\hline 4 & mouse & B56epsilon & 56 & - & Q61151 & $\begin{array}{l}\text { B56 epsilon-specific, }{ }^{b} \mathrm{~B}^{\prime} \text { general (M878, } \\
\text { EFDPEEDEPT; AR-1, ELFDSEDPRER) }\end{array}$ \\
\hline 5 & mouse & $\mathrm{B} \alpha$ & 55 & - & $\mathrm{P} 36876(57)^{d}$ & $\mathrm{~B} \alpha(\mathrm{CFSQVKGAVDDDVA})$ \\
\hline \multirow[t]{2}{*}{6} & mouse & B56delta & 72 & $\operatorname{L} 76702(8,9)^{d}$ & - & $\begin{array}{l}\text { B' general (M878, EFDPEEDEPT; AR-1, } \\
\text { ELFDSEDPRER), striatin (SVGSPSRPSSSRLPE) }\end{array}$ \\
\hline & & 74Kdelta $1^{f}$ & 72 & $\mathrm{AB} 000634(11)^{d}$ & - & \\
\hline \multirow[t]{3}{*}{7} & mouse & $\mathrm{B}^{\prime}$ gamma $^{c}$ & 61 & U38195 & - & $\begin{array}{l}\text { B' general (M878, EFDPEEDEPT; AR-1, } \\
\text { ELFDSEDPRER), striatin (SVGSPSRPSSSRLPE) }\end{array}$ \\
\hline & & $\mathrm{B}^{\prime}$ gamma $2^{c}$ & 61 & $\mathrm{U} 38193(6)^{d}$ & - & \\
\hline & & 74 Kdelta $2^{c}$ & 61 & $\mathrm{U} 78360(11)^{d}$ & - & \\
\hline
\end{tabular}

${ }^{a}$ Protein verified by peptide sequence and described in the text. ${ }^{b}$ Antibody generated from purified retinal protein and described in the text. ${ }^{c}$ These three $\mathrm{B}^{\prime}$ subunits are different proteins, all containing the PPSSNKRPSNSTPPP sequence, and therefore cross react with the B' general and striatin antibodies. ${ }^{d}$ The numbers in parentheses are references. ${ }^{e}$ This protein is identical to B56epsilon. ${ }^{f}$ This protein is identical to B56delta.

A

$\begin{array}{lllllllllll}1 & 3 & 5 & 7 & 9 & 11 & 13 & 15 & 17 & \mathrm{~A}\end{array}$

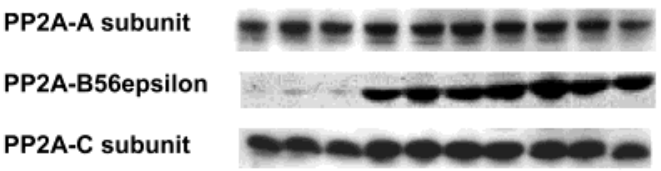

Rod Arrestin

Phosducin

Creatine Kinase

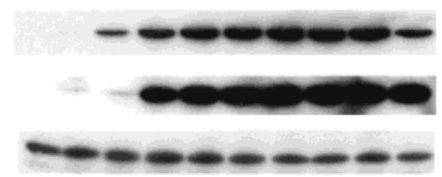

B $\begin{array}{lllllllllll}1 & 3 & 5 & 7 & 9 & 11 & 13 & 15 & 17 & \mathrm{~A}\end{array}$
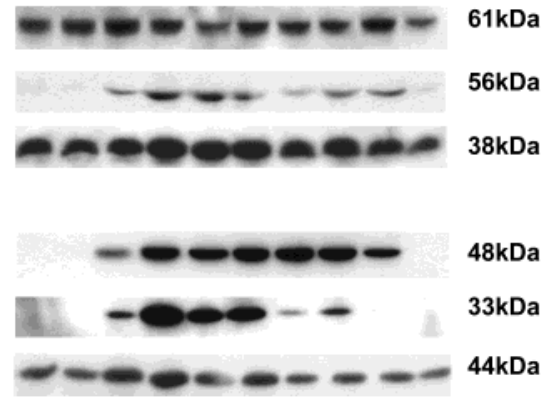

FIGURE 5: Developmental study of control and retinal degeneration $(r d / r d)$ mouse retina. Control $(\mathrm{C} 57 \mathrm{Bl} / 6 \mathrm{~J})(\mathrm{A})$ and $r d / r d(\mathrm{C} 57 \mathrm{Bl} / 6 \mathrm{~J} r d l e)$ (B) mice were sacrificed on postnatal day 1,3, 5, etc. (P1, P3, P5, etc., respectively) and as adults (A), and retinas were dissected. Sixty micrograms of soluble retinal proteins was applied to an $11.5 \%$ SDS-PAGE, electrophoresed, and processed for immunoblot analysis. For primary antibodies, A, B', and C are the same as in Figure 2. Rod arrestin is a monoclonal antibody (C10C10), which recognizes RERRGIALD (amino acids 292-300, S-antigen, accession number A30357); phosducin is Mab1D6, and a control antibody for equal loading and quantitation, creatine kinase, is Pab1948. Molecular masses of proteins are indicated on the right. PP2A A and C subunits remain unchanged throughout the development of both control and $r d$ mice retina. The B56epsilon subunit is absent at P1 and P3 of both strains and in adult $r d$ mice.

In the mouse retina, two other $\mathrm{B}^{\prime}$ subunits, at 72 and 61 $\mathrm{kDa}$, which do not correlate with phosducin dephosphorylation, are in whole retinal homogenates and are cross reactive with the two $\mathrm{B}^{\prime}$ general antibodies (M878 and AR1) (data not shown). These two proteins are also cross reactive with another antibody, against mouse striatin, kindly provided by D. Pallas (Harvard Medical School) (data not shown). This cross reactivity helps identify these two other $\mathrm{B}^{\prime}$ subunits in retina. The mouse striatin antibody peptide, SVGSPSRPSSSRLPE, is partly identical with a portion (PPSSNKRPSNSTPPP) of only one known B' subunit with a predicted molecular mass of $\sim 72 \mathrm{kDa}$, B56delta (nucleotide accession number L76702) (8, 9), which is also identified as 74Kdelta1 (nucleotide accession number AB000634) (11). Three known $\mathrm{B}^{\prime}$ subunits of $\sim 61 \mathrm{kDa}$, closely related to B56delta, also contain this homologous sequence: B'gamma (nucleotide accession number U38195), B'gamma2 (nucleotide accession number U38193) (6), and 74Kdelta2 (nucleotide accession number D78360) (11).

Changes in the B56epsilon Subunit of Retinal PP2A during Development of Normal and rd/rd Mice. Immunoblot analysis reveals that the PP2A A $(61 \mathrm{kDa})$ and C $(38 \mathrm{kDa})$ subunits (Figure 5A,B), along with $\mathrm{B} \alpha(55 \mathrm{kDa})$ (data not shown), are present by postnatal day 1 , in both normal C57 and $r d / r d$ mouse retinas, and remain at almost constant levels throughout development in both strains. The B56epsilon subunit $(56 \mathrm{kDa})$ is below detection at day 1 , appearing only between postnatal days 3 and 5 when rod photoreceptors begin to differentiate in both $\mathrm{C} 57$ and $r d / r d$ mouse retinas (Figure 5A,B). B56epsilon subunit immunoreactivity is absent in mature $r d / r d$ mouse retinas (Figure 5B), which lack differentiated photoreceptors (49). In this respect, the B56epsilon subunit is the only PP2A subunit tested that correlated developmentally with the presence or absence of rod photoreceptors. Endogenous controls reflect this same pattern, with photoreceptor-specific proteins arrestin and phosducin also lacking in early ages of both strains and declining when photoreceptor cells are known to degenerate in the $r d / r d$ mouse (58). As a loading control, retinal creatine kinase, expressed throughout the retina layers, was constant in both normal and $r d / r d$ retinas throughout development. These observations suggest that the B56epsilon subunit and the AC complex of PP2A are present in differentiated rod photoreceptors of mice retinas. 
Light/Dark Redistribution of PP2A Subunits in Mouse Retina. To verify if the substrate preference of the PP2A trimer and dimer correlates with its substrate and subunit distribution in vivo, we separated the cytosolic and membrane fractions of mouse retinas after the mice were exposed to different light conditions and did immunoblot analysis on both fractions with antibodies recognizing selected PP2A subunits. As shown in Figure 6, the PP2A A, B56epsilon, and $\mathrm{C}$ subunits in the mouse retina are redistributed from the cytosolic (soluble) to the membrane fraction (particulate) (Figure 6A, parts a, b, and d) or the reverse (Figure 6B, parts $\mathrm{a}, \mathrm{b}$, and d) within $1.5 \mathrm{~min}$ of the change in the light condition. We estimate the total amount of mouse PP2A A subunit to be $\sim 80 \mathrm{ng} /$ mouse retina, B56epsilon to be $\sim 1.5$ $\mathrm{ng} /$ mouse retina, and $\mathrm{C}$ to be $\sim 40 \mathrm{ng} /$ mouse retina using quantitative Western blot analysis with densitometric scanning of the appropriate band in the mice retina and comparing it to a known amount of insect cell expressed fusion protein of the PP2A A, B', and C subunits analyzed on the same gel. Therefore, the approximate $25 \%$ A subunit translocation represents $\sim 20 \mathrm{ng} /$ mouse retina, the 30\% B56epsilon subunit translocation $\sim 0.45 \mathrm{ng} /$ mouse retina, and the $10 \% \mathrm{C}$ subunit translocation $\sim 4 \mathrm{ng} /$ mouse retina. The $\mathrm{B} \alpha$ subunit does not redistribute [Figure 6A (part c) and Figure 6B (part c)]. Rod arrestin, which binds to phosphorylated rhodopsin during light exposure, becomes associated with the retinal membrane fraction; however, rod arrestin is more abundant in the soluble fraction during dark exposure [Figure 6A (part $\mathrm{f}$ ) and Figure 6B (part f)] (53). The $\beta$ subunit of transducin $(\mathrm{T} \beta)$, which dissociates from membrane-bound $\mathrm{T} \alpha$ upon exposure to light, is noted to translocate from the membrane to the soluble fraction upon light exposure and from the soluble to the membrane fraction during the transition from light to darkness [Figure 6A (part e) and Figure 6B (part e)] (59).

\section{DISCUSSION}

Although indirect evidence relating to PP2A dephosphorylation of rhodopsin and phosducin has accumulated, the retinal photoreceptor PP2A complex has not been characterized. In this report, the subunits of the retinal PP2A complex are identified, PP2A distribution within the retina is described, and light/dark dynamics of retinal PP2A translocation are revealed that clarify a role for one enzyme in ensuring the efficient dephosphorylation of phosducin in the light and rhodopsin in the dark.

Dephosphorylation of proteins by phosphatases is an essential mechanism in regulation of the visual G-protein transduction process, particularly events involved with modulation and downregulation of the rod photoreceptor. Light absorbed by rhodopsin in the rod outer segments causes conformational changes that activate the cascade through a catalyzed exchange of GDP for GTP on the $\alpha$ subunit of transducin $(60,61)$. GDP-GTP exchange releases the $\beta \gamma$ complex of transducin, freeing GTP- $\alpha$-transducin to interact with a phosphodiesterase enzyme that hydrolyzes cGMP, and releasing the transducin $\beta \gamma$ complex to interact with phosducin. As cGMP levels fall, the cGMP-gated channels close and the photoreceptor cell hyperpolarizes. The rod phototransduction cascade provides a mechanism for amplification of the photon signal, but the amplitude of the photon-initiated response can be modulated by phosducin through the binding of the $\beta \gamma$ transducin subunits (26). The $\beta \gamma$ complex must recombine with $\alpha$-transducin before interacting with bleached rhodopsin, and phosducin can limit the availability of the $\beta \gamma$ complex.

During darkness, phosducin is phosphorylated at Ser73 by PKA (62), at the C-terminal domain between residues 204 and 245 and between residues 195 and 218 by GRK2 (63), and at Ser54 and Ser73 by $\mathrm{Ca}^{2+} /$ calmodulin-dependent protein kinase II, leading to the binding of $14-3-3$ protein (64). In these phosphorylated forms, phosducin has a diminished ability to bind $\mathrm{T}_{\beta \gamma}$. Upon exposure to light, phosducin is dephosphorylated by PP2A $(19,21)$. The dephosphorylated species of phosducin, no longer binding 14-3-3 protein, is more efficient in sequestering the $\beta \gamma$ subunits of transducin (65). Therefore, dephosphorylation of phosducin by PP2A establishes the conditions for phosducin to modulate the amplification of cGMP hydrolysis by preventing the recycling of transducin with the activated rhodopsin. In strong light, when maximum modulation is most desirable so that the cascade is not saturated, the net dephosphorylated state of phosducin is ensured by several synergistic mechanisms. The fall in photoreceptor cGMP levels upon illumination results in decreased levels of phosphorylated phosducin, in part because the PKA enzyme that phosphorylates phosducin is also sensitive to cGMP levels (22). Cytosolic $\mathrm{Ca}^{2+}$ levels fall upon illumination of photoreceptors. This drop in $\mathrm{Ca}^{2+}$ levels affects the activity of a $\mathrm{Ca}^{2+}$ /calmodulin-dependent adenylyl cyclase, dropping the levels of cAMP, which, in turn, decreases the level of net cAMP-dependent phosphorylation of phosducin (66). The drop in cytosolic $\mathrm{Ca}^{2+}$ levels also affects the activity of the $\mathrm{Ca}^{2+}$-dependent kinase, decreasing its activity and the net phosphorylation state of phosducin. In this report, we propose an additional mechanism, one involving the light-driven translocation of the PP2A enzyme complex to the cytosolic fraction, which would augment this decrease in the net phosphorylation state of cytosolic phosducin upon illumination.

The activated receptor in G-protein receptor-coupled signaling mechanisms is shut off through a process of phosphorylation by a receptor-specific kinase and the subsequent binding of a protein from the arrestin family (67, 68 ). In retina, light-activated rhodopsin undergoes deactivation via phosphorylation by rhodopsin kinase at multiple $\mathrm{C}$-terminal sites and the subsequent binding of rod arrestin $(32,69-71)$. For rhodopsin to recycle for full light sensitivity, arrestin and the phosphate moieties must be removed. Light-dependent $\mathrm{Ca}^{2+}$ concentration fluctuations have also been shown to affect the dephosphorylation of rhodopsin through the $\mathrm{Ca}^{2+}$-activated opsin phosphatase (CAOP) enzyme (72). In Drosophila, the $\mathrm{Ca}^{2+}$-dependent rhodopsin protein phosphatase, RDGC, dephosphorylates rhodopsin (73). However, in the vertebrate retina, two RDGC homologues, PPEF-1 and PPEF-2, were studied with doubleknockout mice and were eliminated as potential candidates for rhodopsin dephosphorylation (74). It is still thought that, in the vertebrate retina, the dephosphorylation of rhodopsin is carried out, at least in part, by a PP2A enzyme complex $(19,23-25,75)$. While the mechanisms and timing of events that lead to rhodopsin dephosphorylation are still unresolved, the translocation of the PP2A enzyme involved in phosducin dephosphorylation onto the membrane during dark conditions 
A
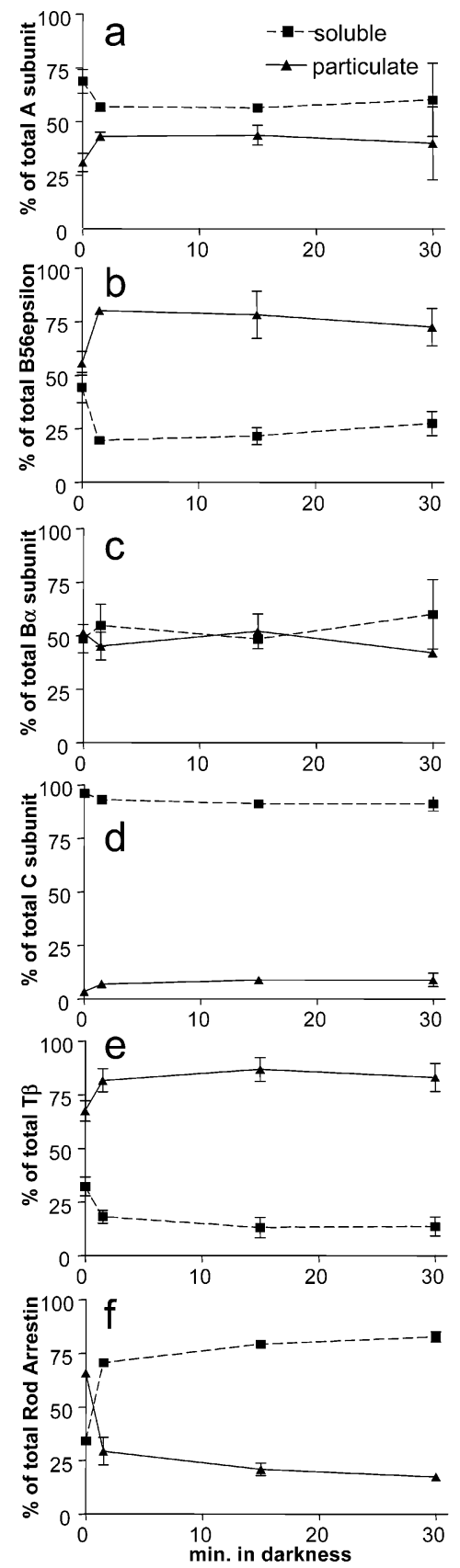

B
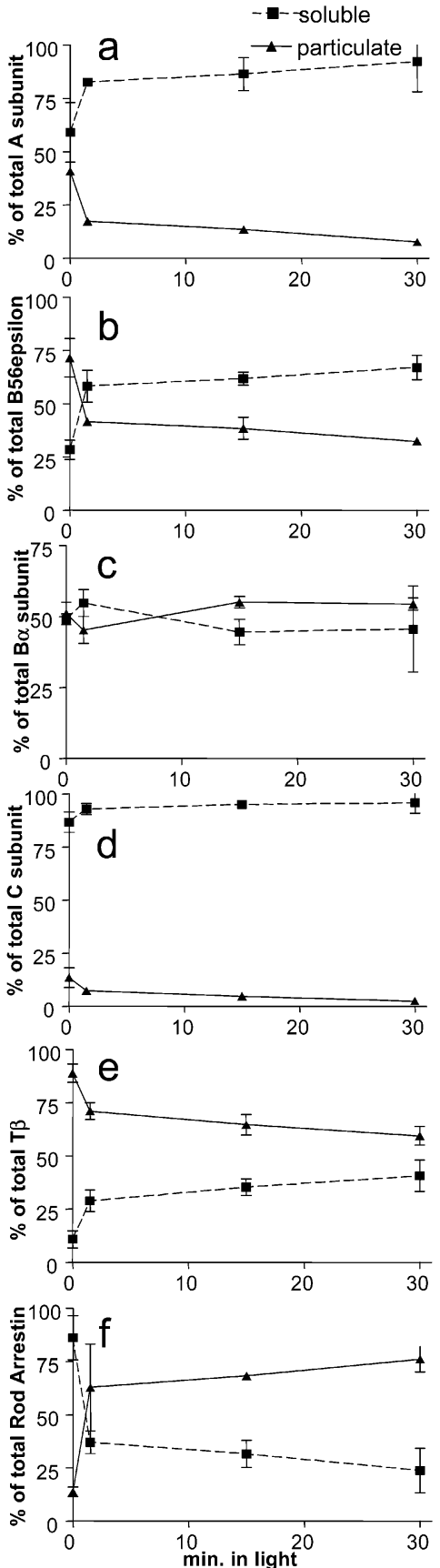

FIGURE 6: Light/dark redistribution of various PP2A subunits in mice retina. Adult C57B1/6J mice were maintained on a $12 \mathrm{~h} / 12 \mathrm{~h} \mathrm{L/D}$ cycle. For the light to dark study (A), a mouse was sacrificed near the midpoint of its light cycle and its retinas were dissected under white light and frozen. Three mice were taken to the dark room and sacrificed at 1.5, 15, and 30 min in the dark. All dark retinas were dissected under infrared light and frozen in foil. For the dark to light study (B), four mice were adapted to the dark for $2 \mathrm{~h}$. One mouse was sacrificed in the dark, and its retinas were dissected. The other mice were taken into the light and were sacrificed after 1.5, 15, and 30 min in the light and the retinas dissected. Both studies were repeated three times. Each retina was homogenized (glass/glass) in $120 \mu \mathrm{L}$ of $50 \mathrm{mM}$ potassium phosphate buffer ( $\mathrm{pH}$ 6.8) with protease inhibitors and was centrifuged at $13000 \mathrm{rpm}$ in a refrigerated microfuge for 10 min into a soluble (ם) and particulate $(\boldsymbol{\Delta})$ fraction. The particulate fractions were resuspended in the same volume and examined, and nuclear membranes were not intact. The dark retinas were processed in the dark. Following a protein determination (Bio-Rad), $30 \mu \mathrm{g}$ of soluble protein and a comparable volume of the particulate fraction from each time point were loaded onto replicate gels, electrophoresed, immunoblotted, and immunodetected by ECL. The quantity of protein antigens was estimated by densitometric scanning of the appropriate band in the mice retina and comparing it to a known amount of insect cell-expressed fusion protein of the PP2A A, B', B $\alpha$, and C subunits analyzed on the same gel. Primary antibodies are the same as in Figure 4. The light and dark condition of the retinas was verified by monitoring S-antigen/ rod arrestin (f), which is associated with membrane in the light, and $\beta$-transducin (e), which is partially soluble in the light, using Mab C10C10 and SC261 (Santa Cruz Biotechnology), respectively. The A (a), B56epsilon (b), and C (d) subunits were all partially redistributed from the soluble $(\mathbf{\square})$ to the membrane $(\boldsymbol{\Delta})$ fraction of the mice retina in the light to dark study (A), even after only $1.5 \mathrm{~min}$ in the dark. The opposite redistribution was seen in the dark to light study (B). The $B \alpha$ (c) subunit was not redistributed. These data are presented as a percent of total soluble and particulate subunit in either the supernatant or the particulate fraction. Because of the large quantity of retinal $\mathrm{A}(80 \mathrm{ng} / \mathrm{retina})$ and $\mathrm{C}$ (40 ng/retina) relative to B56epsilon (1.5 ng/retina), much more A and C subunit is redistributed than B, even though the percentage of redistribution is smaller. After an initial (1.5 min) large redistribution from soluble to membrane-associated A, B, and $\mathrm{C}$ subunits in the transition from light to dark, subsequent time points showed less redistribution. This was not seen in the dark to light study. 


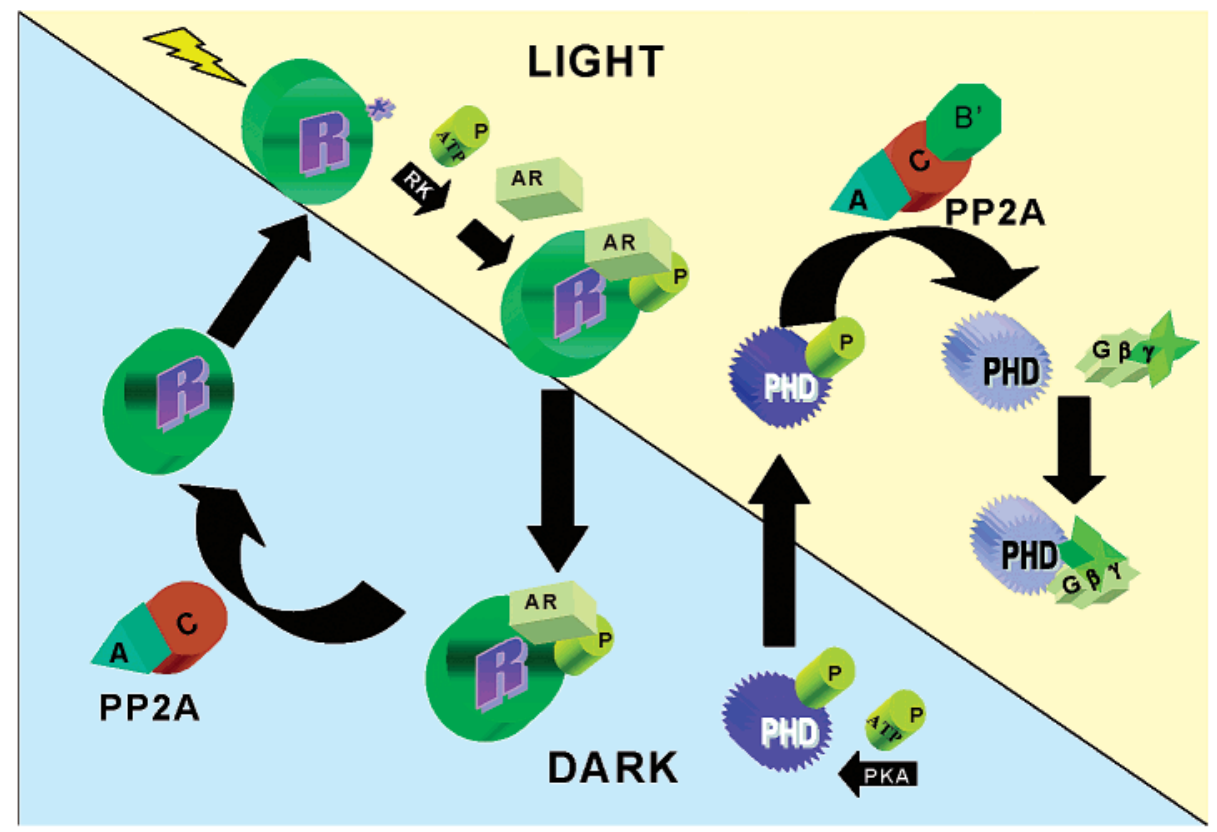

FIGURE 7: Model of changes in the PP2A enzyme during light or dark. The model shows light (lightning bolt) hitting the retina, activating $(*)$ rhodopsin $(\mathrm{R})$, which is phosphorylated $(\mathrm{P})$ by rhodopsin kinase $(\mathrm{RK})$. Rod arrestin (AR) binds to the phosphorylated rhodopsin (R$\mathrm{P}-\mathrm{AR}$ ), helping to downregulate the cascade. Also in the light, phosphorylated phosducin (PHD-P) is dephosphorylated (PHD) by the PP2A trimer (ACB56epsilon), which has moved to the cytosolic fraction of the rod photoreceptor outer segments, favoring the binding of $\beta \gamma$ transducin $(\mathrm{G} \beta \gamma)$, a condition which supplements the downregulation of the cascade. Under dark conditions, PP2A subunits, especially the $\mathrm{A}$ and $\mathrm{C}$ subunits (AC), become associated with the membrane of the rod outer segments and slowly dephosphorylate rhodopsin, resulting in dissociation of the arrestin, and the priming of rhodopsin for another incoming photon of light. Also under dark conditions, phosducin (PHD) is phosphorylated by cyclic AMP-dependent protein kinase (PKA) and other kinases, which results in a form of phosducin (PHD-P), which has lower binding affinity with transducin $(\mathrm{G} \beta \gamma)$.

may contribute to the net dephosphorylation state of rhodopsin during these conditions.

Developmental studies of mice with normal retinas and with retinal degeneration demonstrate that the B56epsilon subunit of PP2A is concentrated in rod photoreceptors (Figure 5). Numerous B subunits are known regulators of PP2A, but only the soluble $56 \mathrm{kDa}$ B56epsilon subunit is associated with the PP2A dephosphorylation activity targeted to phosducin in rod photoreceptor cells (Figure 5), and the presence of this regulatory subunit is strongly associated with the substrate specificity of PP2A for phosducin (Figure 3).

Previous reports suggest that, for PP2A to be fully active against some substrates, the enzyme must first be subjected to denaturing conditions. Ethanol treatment of PP2A releases a pool of latent enzyme activity against phosphorylated rhodopsin, and it was suggested that this might selectively denature the regulatory subunit (20). Ethanol treatment was especially effective on $\operatorname{PrP}-2 \mathrm{~A}_{0}$, which contains the $\mathrm{B}^{\prime}$ subunit, compared to PrP-2 $\mathrm{A}_{1}$, which contains the $\mathrm{B}$ subunit. From these data, it was speculated that rod cell outer segments contained mostly $\operatorname{PrP}-2 \mathrm{~A}_{0}\left(\mathrm{AB}^{\prime} \mathrm{C}\right)$ because the PP2A activity against rhodopsin was so easily stimulated by ethanol treatment. Using gel filtration chromatography, other investigators eluted peak bovine ROS phosphatase activity against phosphorylated opsin or rhodopsin at 100 $\mathrm{kDa}$, suggesting that the dimeric form of the PP2A enzyme $\left(\mathrm{PP} 2 \mathrm{~A}_{2}\right)$ was most active against these substrates $(23,24)$. Still other experiments noted that freezing and thawing treatment under reducing conditions dissociates oligomeric forms of PP2A and leads to a 9-fold activation of this enzyme when using phosphorylase $a$ as a substrate (76). These observations are consistent with our results that clearly demonstrate that the dimeric form of PP2A, lacking the $\mathrm{B}^{\prime}$ subunit, is more active against phosphorylated opsin and phosphorylase $a$ than the trimer form (Figure 3).

The retinal PP2A trimer complex containing the $\mathrm{B}^{\prime}$ subunit undergoes changes throughout the light/dark cycle, which are dependent on ambient light conditions and not an intrinsic circadian rhythm. Upon exposure to light, the soluble protein level of AC-B56epsilon increases, while that of the membrane-associated AC-B56epsilon decreases. The level of soluble trimer is highest when phosducin is dephosphorylated in light, favoring the binding of $\beta \gamma$-transducin and downregulation of the visual cascade. A return to dark conditions causes the soluble trimer level to fall and the level of the membrane-bound enzyme complex to increase. Because approximately 10-fold as much $\mathrm{A}$ and $\mathrm{C}$ subunits redistribute to the membrane as B56epsilon, the enzyme on the membrane in the dark is predominately a dimer (although other $\mathrm{B}$ subunits may be associated with the AC complex on the membrane, at least the other $\mathrm{B}$ subunit tested, $\mathrm{B} \alpha$, is not redistributed). It was demonstrated that the PP2A dimer (AC) dephosphorylates phosphorylase $a$ and opsin more efficiently than the trimer, while the PP2A trimer (AC-B56epsilon) dramatically catalyzes the dephosphorylation of phosducin and histone (Figure 3 ). These findings suggest that additional $\mathrm{A}$ and $\mathrm{C}$ subunits on the membrane under dark conditions result in a more efficient rhodopsin dephosphorylation.

The PP2A dimer dephosphorylation rate we observe, using opsin as a substrate, is extremely low (Figure 3C) compared to the rate for other substrates that were tested, particularly that of phosducin by the PP2A trimer. This could be explained in several ways. It is possible that, under our experimental conditions, we are not observing the full opsin 
activity. The PP2A enzyme assay was optimized for phosducin dephosphorylation and may not have contained all the essential factors necessary for optimal opsin dephosphorylation. Protamine and dopamine have been shown to influence opsin dephosphorylation by PP2A $(24,77)$. It has been suggested that, before Ser334 of opsin can be dephosphorylated, opsin must first be regenerated with 11-cis-retinal (78). As our opsin substrate was not regenerated, this may account for the low rate of dephosphorylation. Alternatively, the slower rate of opsin dephosphorylation by the dimer of PP2A in the dark described here may have physiological significance in being a part of the slow dark adaptation phase. Dephosphorylation of opsin at Ser334, the residue phosphorylated and dephospharylated at the slowest rate, proceeds at a rate consistent with the slow dark adaptation phase (halftime of approximately $40 \mathrm{~min}$ ) (78).

Our observations are summarized in a model that illustrates the translocation that occurs in the PP2A enzyme under light or dark conditions (Figure 7). The model intends to focus our findings on the functional implications of this translocation of the PP2A enzyme complex. The model depicts a shift in the distribution of the PP2A complex from the membrane to the soluble fraction, upon the transition of rod photoreceptors to light conditions. The PP2A dimer is predominant on the membranes during darkness because of the additional $\mathrm{A}$ and $\mathrm{C}$ subunits that are redistributed. The model shows that the level of the soluble AC-B56epsilon trimer is higher when phosducin is dephosphorylated in light, favoring the binding of $\beta \gamma$-transducin and downregulation of the visual cascade. Correspondingly, the PP2A dimer is prevalent on the membrane in darkness when maximum sensitivity is needed, ensuring that the membrane-embedded rhodopsin is dephosphorylated and made ready for another photon capture.

\section{ACKNOWLEDGMENT}

After this work was completed, our lifetime collaborator and friend, Dr. R. N. Lolley, died. Dr. Lolley made significant contributions to vision research over the course of 30 years, including the discovery that the biochemical defect in the $r d / r d$ mouse retina is the $\beta$ PDE enzyme (79). We thank Drs. C. Kamibayashi and M. C. Mumby for the gifts of antibodies for the PP2A subunits, Dr. L. A. Donoso for the monoclonal antibodies for rod arrestin $(\mathrm{C} 10 \mathrm{C} 10)$ and phosducin (1D6), and Dr. D. Pallas for the AR-1 and striatin antibodies. We also acknowledge work contributed by Dr. Rehwa H. Lee (Veterans Administration Medical Center, Sepulveda, CA) in earlier isolation of the bovine retina PP2A complex and Miss Ashwini Lakshmanan (Med II, Keck School of Medicine) and Yushun Zhang for editorial and technical assistance with the manuscript.

\section{REFERENCES}

1. Khew-Goodall, Y., Mayer, R. E., Maurer, F., Stone, S. R., and Hemmings, B. A. (1991) Structure and transcriptional regulation of protein phosphatase $2 \mathrm{~A}$ catalytic subunit genes, Biochemistry 30, 89-97.

2. Hemmings, B. A., Adams-Pearson, C., Maurer, F., Muller, P., Goris, J., Merlevede, W., Hofsteenge, J., and Stone, S. R. (1990) alpha- and beta-forms of the $65-\mathrm{kDa}$ subunit of protein phosphatase 2A have a similar 39 amino acid repeating structure, Biochemistry 29, 3166-3173.
3. Price, N. E., Wadzinski, B., and Mumby, M. C. (1999) An anchoring factor targets protein phosphatase $2 \mathrm{~A}$ to brain microtubules, Brain Res. Mol. Brain Res. 73, 68-77.

4. Mayer, R. E., Hendrix, P., Cron, P., Matthies, R., Stone, S. R., Goris, J., Merlevede, W., Hofsteenge, J., and Hemmings, B. A. (1991) Structure of the 55-kDa regulatory subunit of protein phosphatase 2A: evidence for a neuronal-specific isoform, Biochemistry 30, 3589-3597.

5. Hendrix, P., Mayer-Jackel, R. E., Cron, P., Goris, J., Hofsteenge, J., Merlevede, W., and Hemmings, B. A. (1993) Structure and expression of a $72-\mathrm{kDa}$ regulatory subunit of protein phosphatase 2A. Evidence for different size forms produced by alternative splicing, J. Biol. Chem. 268, 15267-15276.

6. Csortos, C., Zolnierowicz, S., Bako, E., Durbin, S. D., and DePaoliRoach, A. A. (1996) High complexity in the expression of the B' subunit of protein phosphatase 2A0. Evidence for the existence of at least seven novel isoforms, J. Biol. Chem. 271, 2578-2588.

7. McCright, B., and Virshup, D. M. (1995) Identification of a new family of protein phosphatase $2 \mathrm{~A}$ regulatory subunits, J. Biol. Chem. 270, 26123-26128.

8. McCright, B., Rivers, A. M., Audlin, S., and Virshup, D. M. (1996) The B56 family of protein phosphatase 2A (PP2A) regulatory subunits encodes differentiation-induced phosphoproteins that target PP2A to both nucleus and cytoplasm, J. Biol. Chem. 271, 22081-22089

9. McCright, B., Brothman, A. R., and Virshup, D. M. (1996) Assignment of human protein phosphatase $2 \mathrm{~A}$ regulatory subunit genes b56alpha, b56beta, b56gamma, b56delta, and b56epsilon (PPP2R5A-PPP2R5E), highly expressed in muscle and brain, to chromosome regions 1q41, 11q12, 3p21, 6p21.1, and 7p11.2 $\rightarrow$ p12, Genomics 36, 168-170.

10. Zolnierowicz, S., Van Hoof, C., Andjelkovic, N., Cron, P., Stevens, I., Merlevede, W., Goris, J., and Hemmings, B. A. (1996) The variable subunit associated with protein phosphatase $2 \mathrm{~A} 0$ defines a novel multimember family of regulatory subunits, Biochem. $J$. $317,187-194$

11. Tanabe, O., Nagase, T., Murakami, T., Nozaki, H., Usui, H., Nishito, Y., Hayashi, H., Kagamiyama, H., and Takeda, M. (1996) Molecular cloning of a 74-kDa regulatory subunit (B" or delta) of human protein phosphatase 2A, FEBS Lett. 379, 107-111.

12. Zolnierowicz, S., Csortos, C., Bondor, J., Verin, A., Mumby, M. C., and DePaoli-Roach, A. A. (1994) Diversity in the regulatory B-subunits of protein phosphatase 2A: identification of a novel isoform highly expressed in brain, Biochemistry 33, 11858-11867.

13. Tehrani, M. A., Mumby, M. C., and Kamibayashi, C. (1996) Identification of a novel protein phosphatase $2 \mathrm{~A}$ regulatory subunit highly expressed in muscle, J. Biol. Chem. 271, 5164-5170.

14. Okamoto, K., Kamibayashi, C., Serrano, M., Prives, C., Mumby, M. C., and Beach, D. (1996) p53-dependent association between cyclin $\mathrm{G}$ and the $\mathrm{B}^{\prime}$ subunit of protein phosphatase 2A, Mol. Cell. Biol. 16, 6593-6602.

15. Healy, A. M., Zolnierowicz, S., Stapleton, A. E., Goebl, M., DePaoli-Roach, A. A., and Pringle, J. R. (1991) CDC55, a Saccharomyces cerevisiae gene involved in cellular morphogenesis: identification, characterization, and homology to the B subunit of mammalian type 2A protein phosphatase, Mol. Cell. Biol. 11, 5767-5780.

16. Strack, S., Zaucha, J. A., Ebner, F. F., Colbran, R. J., and Wadzinski, B. E. (1998) Brain protein phosphatase 2A: developmental regulation and distinct cellular and subcellular localization by B subunits, J. Comp. Neurol. 392, 515-527.

17. Zhu, T., Matsuzawa, S., Mizuno, Y., Kamibayashi, C., Mumby, M. C., Andjelkovic, N., Hemmings, B. A., Onoe, K., and Kikuchi, K. (1997) The interconversion of protein phosphatase 2A between PP2A1 and PP2A0 during retinoic acid-induced granulocytic differentiation and a modification on the catalytic subunit in $\mathrm{S}$ phase of HL-60 cells, Arch. Biochem. Biophys. 339, 210-217.

18. Walter, G., Ruediger, R., Slaughter, C., and Mumby, M. (1990) Association of protein phosphatase $2 \mathrm{~A}$ with polyoma virus medium tumor antigen, Proc. Natl. Acad. Sci. U.S.A. 87, 25212525.

19. Lee, R. H., and Brown, B. M. (1991) Phosphoprotein phosphatases of bovine retinas: purification and characterization, Invest. Ophthalmol. Visual Sci. 32, 1894.

20. Palczewski, K., Hargrave, P. A., McDowell, J. H., and Ingebritsen, T. S. (1989) The catalytic subunit of phosphatase 2A dephosphorylates phosphoopsin, Biochemistry 28, 415-419.

21. Pagh-Roehl, K., Lin, D., Su, L., and Burnside, B. (1995) Phosducin and PP33 are in vivo targets of PKA and type 1 or $2 \mathrm{~A}$ 
phosphatases, regulators of cell elongation in teleost rod innerouter segments, J. Neurosci. 15, 6475-6488.

22. Lee, R. H., Brown, B. M., and Lolley, R. N. (1984) Light-induced dephosphorylation of a $33 \mathrm{~K}$ protein in rod outer segments of rat retina, Biochemistry 23, 1972-1977.

23. Fowles, C., Akhtar, M., and Cohen, P. (1989) Interplay of phosphorylation and dephosphorylation in vision: protein phosphatases of bovine rod outer segments, Biochemistry 28, 93859391.

24. King, A. J., Andjelkovic, N., Hemmings, B. A., and Akhtar, M. (1994) The phospho-opsin phosphatase from bovine rod outer segments. An insight into the mechanism of stimulation of type2 A protein phosphatase activity by protamine, Eur. J. Biochem. 225, 383-394.

25. Ohguro, H., Van Hooser, J. P., Milam, A. H., and Palczewski, K. (1995) Rhodopsin phosphorylation and dephosphorylation in vivo, J. Biol. Chem. 270, 14259-14262.

26. Lee, R. H., Ting, T. D., Lieberman, B. S., Tobias, D. E., Lolley, R. N., and Ho, Y. K. (1992) Regulation of retinal cGMP cascade by phosducin in bovine rod photoreceptor cells. Interaction of phosducin and transducin, J. Biol. Chem. 267, 25104-25112.

27. Yoshida, T., Willardson, B. M., Wilkins, J. F., Jensen, G. J., Thornton, B. D., and Bitensky, M. W. (1994) The phosphorylation state of phosducin determines its ability to block transducin subunit interactions and inhibit transducin binding to activated rhodopsin, J. Biol. Chem. 269, 24050-24057.

28. Hawes, B. E., Touhara, K., Kurose, H., Lefkowitz, R. J., and Inglese, J. (1994) Determination of the G beta gamma-binding domain of phosducin. A regulatable modulator of $\mathrm{G}$ beta gamma signaling, J. Biol. Chem. 269, 29825-29830.

29. Lolley, R. N., Brown, B. M., and Farber, D. B. (1977) Protein phosphorylation in rod outer segments from bovine retina: cyclic nucleotide-activated protein kinase and its endogenous substrate, Biochem. Biophys. Res. Commun. 78, 572-578.

30. Zhu, X., and Craft, C. M. (1998) Interaction of phosducin and phosducin isoforms with a $26 \mathrm{~S}$ proteasomal subunit, SUG1, Mol. Vision 4, 13.

31. Zhu, X., and Craft, C. M. (2000) Modulation of CRX transactivation activity by phosducin isoforms, Mol. Cell. Biol. 20, 52165226.

32. Shichi, H., and Somers, R. L. (1978) Light-dependent phosphorylation of rhodopsin. Purification and properties of rhodopsin kinase, J. Biol. Chem. 253, 7040-7046.

33. Kuhn, H., and Wilden, U. (1987) Deactivation of photoactivated rhodopsin by rhodopsin-kinase and arrestin, J. Recept. Res. 7, 283-298.

34. Hardie, R. (2002) Adaptation through translocation, Neuron 34, $3-5$.

35. Sokolov, M., Lyubarsky, A. L., Strissel, K. J., Savchenko, A. B., Govardovskii, V. I., Pugh, E. N., Jr., and Arshavsky, V. Y. (2002) Massive light-driven translocation of transducin between the two major compartments of rod cells: a novel mechanism of light adaptation, Neuron 34, 95-106.

36. McGinnis, J. F., Matsumoto, B., Whelan, J. P., and Cao, W. (2002) Cytoskeleton participation in subcellular trafficking of signal transduction proteins in rod photoreceptor cells, J. Neurosci. Res. 67, 290-297.

37. Whelan, J. P., and McGinnis, J. F. (1988) Light-dependent subcellular movement of photoreceptor proteins, J. Neurosci. Res. 20, 263-270.

38. Kuo, C. H., and Miki, N. (1989) Translocation of a photoreceptorspecific MEKA protein by light, Neurosci. Lett. 103, 8-10.

39. Terakita, A., Takahama, H., Tamotsu, S., Suzuki, T., Hariyama, T., and Tsukahara, Y. (1996) Light-modulated subcellular localization of the alpha-subunit of GTP-binding protein Gq in crayfish photoreceptors, Visual Neurosci. 13, 539-547.

40. Frixione, E., and Tsutsumi, V. (1982) Photomechanical responses in crustacean retinula cells: the role of microtubules, Vision Res. 22, 1507-1514.

41. Bronstein, J., Wasterlain, C. G., Lasher, R., and Farber, D. B. (1989) Dark-induced changes in activity and compartmentalization of retinal calmodulin kinase in the rat, Brain Res. 495, 83-88.

42. Bahner, M., Frechter, S., Da Silva, N., Minke, B., Paulsen, R., and Huber, A. (2002) Light-regulated subcellular translocation of Drosophila TRPL channels induces long-term adaptation and modifies the light-induced current, Neuron 34, 83-93.

43. Antoniw, J. F., Nimmo, H. G., Yeaman, S. J., and Cowen, P. (1977) Comparison of the substrate specificities of protein phosphatases involved in the regulation of glycogen metabolism in rabbit skeletal muscle, Biochem. J. 162, 423-433.

44. Shenolikar, S., and Ingebritsen, T. S. (1984) Protein (serine and threonine) phosphate phosphatases, Methods Enzymol. 107, 102129.

45. Farber, D. B., and Lolley, R. N. (1979) Phosphoproteins as proposed modulators of visual function, Adv. Exp. Med. Biol. 116, $103-115$.

46. Kuhn, H., and Wilden, U. (1982) Assay of phosphorylation of rhodopsin in vitro and in vivo, Methods Enzymol. 81, 489-496.

47. Navon, S. E., Lee, R. H., Lolley, R. N., and Fung, B. K. (1987) Immunological determination of transducin content in retinas exhibiting inherited degeneration, Exp. Eye Res. 44, 115-125.

48. Wilden, U., and Kuhn, H. (1982) Light-dependent phosphorylation of rhodopsin: number of phosphorylation sites, Biochemistry 21, 3014-3022.

49. LaVail, M. M., and Sidman, R. L. (1974) C57BL-6J mice with inherited retinal degeneration, Arch. Ophthalmol. 91, 394-400.

50. Lolley, R. N., Farber, D. B., Rayborn, M. E., and Hollyfield, J. G. (1977) Cyclic GMP accumulation causes degeneration of photoreceptor cells: simulation of an inherited disease, Science 196, 664-666.

51. Towbin, H., Staehelin, T., and Gordon, J. (1979) Electrophoretic transfer of proteins from polyacrylamide gels to nitrocellulose sheets: procedure and some applications, Proc. Natl. Acad. Sci. U.S.A. 76, 4350-4354.

52. Craft, C. M., Xu, J., Slepak, V. Z., Zhan-Poe, X., Zhu, X., Brown, B., and Lolley, R. N. (1998) PhLPs and PhLOPs in the phosducin family of $\mathrm{G}$ beta gamma binding proteins, Biochemistry 37 , $15758-15772$

53. Craft, C. M., Whitmore, D. H., and Donoso, L. A. (1990) Differential expression of mRNA and protein encoding retinal and pineal S-antigen during the light/dark cycle, J. Neurochem. 55, $1461-1473$.

54. Kamibayashi, C., Estes, R., Lickteig, R. L., Yang, S. I., Craft, C., and Mumby, M. C. (1994) Comparison of heterotrimeric protein phosphatase 2A containing different B subunits, J. Biol. Chem. 269, 20139-20148.

55. Mumby, M. C., Russell, K. L., Garrard, L. J., and Green, D. D. (1987) Cardiac contractile protein phosphatases. Purification of two enzyme forms and their characterization with subunit-specific antibodies, J. Biol. Chem. 262, 6257-6265.

56. Craft, C., Ho, L., Vu, L., Brown, B., and Lolley, R. (1996) Differential localization of arrestin and carrestin within the retina and brain, Invest. Ophthalmol. Visual Sci. 37, 4340.

57. Pallas, D. C., Weller, W., Jaspers, S., Miller, T. B., Lane, W. S., and Roberts, T. M. (1992) The third subunit of protein phosphatase 2A (PP2A), a 55-kilodalton protein which is apparently substituted for by $\mathrm{T}$ antigens in complexes with the 36- and 63-kilodalton PP2A subunits, bears little resemblance to T antigens, J. Virol. 66, 886-893.

58. Lee, R. H., Lieberman, B. S., and Lolley, R. N. (1990) Retinal accumulation of the phosducin/T $\beta \gamma$ and transducin complexes in developing normal mice and dogs with inherited retinal degeneration, Exp. Eye Res. 51, 325-333.

59. Lee, R. H., Whelan, J. P., Lolley, R. N., and McGinnis, J. F. (1988) The photoreceptor-specific $33 \mathrm{kDa}$ phosphoprotein of mammalian retina: generation of monospecific antibodies and localization by immunocytochemistry, Exp. Eye Res. 46, 829-840.

60. Fung, B. K.-K., and Stryer, L. (1980) Photolyzed rhodopsin catalyzes the exchange of GTP for bound GDP in retinal rod outer segments, Proc. Natl. Acad. Sci. U.S.A. 77, 2500-2504.

61. Fung, B. K.-K., Hurley, J. B., and Stryer, L. (1981) Flow of information in the light-triggered cyclic nucleotide cascade of vision, Proc. Natl. Acad. Sci. U.S.A. 78, 152-156.

62. Lee, R. H., Brown, B. M., and Lolley, R. N. (1990) Protein kinase A phosphorylates retinal phosducin on serine 73 in situ, J. Biol. Chem. 265, 15860-15866.

63. Ruiz-Gomez, A., Humrich, J., Murga, C., Quitterer, U., Lohse, M. J., and Mayor, F., Jr. (2000) Phosphorylation of phosducin and phosducin-like protein by $\mathrm{G}$ protein-coupled receptor kinase 2, J. Biol. Chem. 275, 29724-29730.

64. Thulin, C. D., Savage, J. R., McLaughlin, J. N., Truscott, S. M., Old, W. M., Ahn, N. G., Resing, K. A., Hamm, H. E., Bitensky, M. W., and Willardson, B. M. (2001) Modulation of the G protein regulator phosducin by $\mathrm{Ca}^{2+} /$ calmodulin-dependent protein kinase II phosphorylation and 14-3-3 protein binding, J. Biol. Chem. $276,23805-23815$. 
65. Gaudet, R., Savage, J. R., McLaughlin, J. N., Willardson, B. M., and Sigler, P. B. (1999) A molecular mechanism for the phosphorylation-dependent regulation of heterotrimeric $\mathrm{G}$ proteins by phosducin, Mol. Cell 3, 649-660.

66. Willardson, B. M., Wilkins, J. F., Yoshida, T., and Bitensky, M. W. (1996) Regulation of phosducin phosphorylation in retinal rods by $\mathrm{Ca}^{2+} /$ calmodulin-dependent adenylyl cyclase, Proc. Natl. Acad. Sci. U.S.A. 93, 1475-1479.

67. Zhang, J., Ferguson, S. S., Barak, L. S., Aber, M. J., Giros, B., Lefkowitz, R. J., and Caron, M. G. (1997) Molecular mechanisms of $\mathrm{G}$ protein-coupled receptor signaling: role of $\mathrm{G}$ protein-coupled receptor kinases and arrestins in receptor desensitization and resensitization, Recept. Channels 5, 193-199.

68. Craft, C. M., Whitmore, D. H., and Wiechmann, A. F. (1994) cone arrestin identified by targeting expression of a functional Family, J. Biol. Chem. 269, 4613-4619.

69. Palczewski, K., and Benovic, J. L. (1991) G-protein-coupled receptor kinases, Trends Biochem. Sci. 16, 387-391.

70. Pfister, C., Chabre, M., Plouet, J., Tuyen, V. V., De Kozak, Y., Faure, J. P., and Kuhn, H. (1985) Retinal S antigen identified as the $48 \mathrm{~K}$ protein regulating light-dependent phosphodiesterase in rods, Science 228, 891-893.

71. Mendez, A., Burns, M. E., Roca, A., Lem, J., Wu, L. W., Simon, M. I., Baylor, D. A., and Chen, J. (2000) Rapid and reproducible deactivation of rhodopsin requires multiple phosphorylation sites, Neuron 28, 153-164.

72. Kutuzov, M. A., and Bennett, N. (1996) Calcium-activated opsin phosphatase activity in retinal rod outer segments, Eur. J. Biochem. $238,613-622$.
73. Lee, S. J., and Montell, C. (2001) Regulation of the rhodopsin protein phosphatase, RDGC, through interaction with calmodulin, Neuron 32, 1097-1106.

74. Ramulu, P., Kennedy, M., Xiong, W. H., Williams, J., Cowan, M., Blesh, D., Yau, K. W., Hurley, J. B., and Nathans, J. (2001) Normal light response, photoreceptor integrity, and rhodopsin dephosphorylation in mice lacking both protein phosphatases with EF hands (PPEF-1 and PPEF-2), Mol. Cell. Biol. 21, 8605-8614.

75. Palczewski, K., Farber, D. B., and Hargrave, P. A. (1991) Elevated level of protein phosphatase $2 \mathrm{~A}$ activity in retinas of rd mice, Exp. Eye Res. 53, 101-105.

76. Pitcher, J. A., Payne, E. S., Csortos, C., DePaoli-Roach, A. A., and Lefkowitz, R. J. (1995) The G-protein-coupled receptor phosphatase: a protein phosphatase type $2 \mathrm{~A}$ with a distinct subcellular distribution and substrate specificity, Proc. Natl. Acad. Sci. U.S.A. 92, 8343-8347.

77. Udovichenko, I. P., Newton, A. C., and Williams, D. S. (1998) Regulation of the phosphorylation state of rhodopsin by dopamine, J. Biol. Chem. 273, 7181-7184.

78. Kennedy, M. J., Lee, K. A., Niemi, G. A., Craven, K. B., Garwin, G. G., Saari, J. C., and Hurley, J. B. (2001) Multiple phosphorylation of rhodopsin and the in vivo chemistry underlying rod photoreceptor dark adaptation, Neuron 31, 87-101.

79. Lolley, R. N. (1994) The rd gene defect triggers programmed rod cell death. The Proctor Lecture. Invest. Ophthalmol. Visual Sci. $35,4182-4191$.

BI0204490 